\title{
Immature stages and phylogenetic importance of Astrapaeus, a rove beetle genus of puzzling systematic position (Coleoptera, Staphylinidae, Staphylinini)
}

\author{
Ewa Pietrykowska-Tudruj ${ }^{1,4}$, Bernard Staniec ${ }^{1}$, Tadeusz Wojas ${ }^{2}$, Alexey Solodovnikov ${ }^{3}$ \\ ${ }^{1}$ Department of Zoology, Maria-Curie Sklodowska University, Akademicka 19 Street, 20-033 Lublin, Poland \\ ${ }^{2}$ Department of Forest Protection, Entomology and Climatology, University of Agriculture, Al. 29 Listopada 46, \\ 31-425 Cracow, Poland \\ ${ }^{3}$ Zoological Museum, Natural History Museum of Denmark, Universitetsparken 15, Copenhagen, 2100, Denmark \\ ${ }^{4}$ E-mail: ewpiet@wp.pl
}

Key words: egg, feeding preference, larva, life cycle, morphology, phylogeny, pupa

\begin{abstract}
For the first time eggs, larvae and pupae obtained by rearing are described for Astrapaeus, a monotypic West Palearctic rove beetle genus of a puzzling phylogenetic position within the megadiverse tribe Staphylinini. Morphology of the immature stages of Astrapaeus ulmi is compared to that of other members of the tribe and discussed in a phylogenetic context. Contrary to conventional systematics and in accordance with recently developed phylogenetic hypotheses based on morphology of adults, larval morphology supports the non-Quediina affiliation of Astrapaeus. Eggs and pupae provided fewer characters with putative phylogenetic signal. Under laboratory conditions, a peculiar preference for isopod prey was observed for A. ulmi. However, this could not be evaluated in an evolutionary context because of the lack of data on the diet of this and related taxa in nature.
\end{abstract}

\section{Contents}

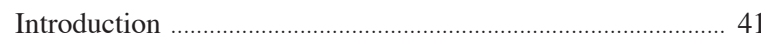

Material and methods .................................................................... 42

Experimental material ........................................................... 42

Study techniques ................................................................... 42

Measurements and their abbreviations ............................ 43

Results ................................................................................ 43

Phylogenetic relationships of Astrapaeus based on adult morphology ............................................................... 43

Taxonomy, distribution, and bionomics of

Astrapaeus ulmi ................................................................. 43

Description of the immature stages ...................................... 46

Life history of Astrapaeus ulmi under laboratory

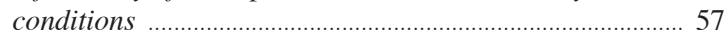

Observed diet preference of Astrapaeus ulmi ............................ 60

Possible phylogenetic signal of the immature stages

of Astrapaeus for the tribe Staphylinini ............................. 61

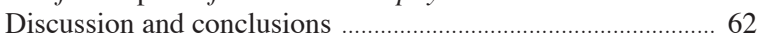

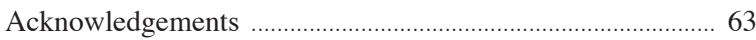

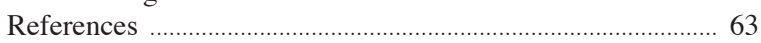

\section{Introduction}

The rove beetle tribe Staphylinini is one of the largest evolutionary radiations in the animal world and took place from about the Early Cretaceous on a global scale (Solodovnikov et al., 2013). Naturally, the phylogenetic reconstruction and classification of such a group is a complex task constrained by methodological limitations. One limitation is a bias towards adult morphology as a source of data for phylogenetic reconstruction due to the lack of alternatives like DNA sequences, morphology of the immature stages, fossils, and biological or ecological traits. Characters of adult macro-morphology, frequently used in classification, are a predominant source for phylogeny reconstruction. However, these characters can be uninformative or even misleading. In Staphylinini this is true for some highly derived autapomorphic groups (e.g., mammal-mutualistic Amblyopinina, subcortical Holisus, some termito- or myrmecophilous genera), or groups with a puzzling combination of characters (e.g., Antimerus, Algon, Bolitogyrus, genera of the so-called 'Acylophorus-complex').

The monotypic genus Astrapaeus Gravenhorst, 1802 , resembling and traditionally placed in the subtribe Quediina, is one such taxon with somewhat unclear sister relationships. Recent phylogenetic research based on adult morphology (Solodovnikov, 2006; Solodovnikov and Schomann, 2009; Brunke and Solodovnikov, 2013) and including fossil taxa (Solodovnikov et al., 2013) suggests that Astrapaeus is not related to Quediina but, instead, is a member of a rather isolated and more basal lineage within Staphylinini with a relict distribution. The most recent phylogeny of Staphylinini using molecular data did not include 
Astrapaeus or its presumed relatives due to a lack of DNA-grade specimens.

Morphology of the immature stages, especially larvae, is an obvious alternative source of phylogenetic information. The utility of larval characters for inferring phylogenetic relationships among lineages within the tribe Staphylinini is not fully understood but larvae of the tribe display a morphological variation worth exploring (Pietrykowska-Tudruj et al., 2012). Finally, the behaviour, habitat preference, diet, and other biological traits either of adults or larvae have never been used for phylogenetic inference in the tribe Staphylinini, although their potential was noticed long ago, at least for the family Staphylinidae as a whole (Tikhomirova, 1973). Therefore, when we discovered the immature stages of the phylogenetically isolated genus Astrapaeus and made some observations on its life cycle and feeding under laboratory conditions, we found it worthwhile not only to describe these new data but also to evaluate them in a broader phylogenetic context of the tribe Staphylinini.

\section{Material and methods}

\section{Experimental material}

Adults of Astrapaeus ulmi were collected on March 29, 2011 under stones from an abandoned limestone quarry in Cracov-Mydlniki, at the southern boundary of the Krakowsko-Częstochowska Upland (N: $50^{\circ} 05^{\prime} 45^{\prime \prime}$ E: 1950'30"; UTM: DA14). Live beetles were placed in a plastic container filled with humid soil and observed in the laboratory from April 1 to June 24, 2011. All immature stages of A. ulmi were obtained by rearing from eggs laid by 3 females kept in the laboratory with 1 male $\left(22 \pm 2^{\circ} \mathrm{C}\right)$. Larvae of various undetermined species of ants and immature Porcelio isopods were supplied as a source of adult food.

Sixty-nine eggs were consecutively isolated on moist filter paper and placed in individual, transparent containers filled with humid soil. Initially, springtails and then immature Porcelio isopods were supplied as food of newly hatched larvae. When the larvae of successive instars and prepupae were obtained, several individuals that reached those stages were killed and preserved. Remaining specimens suspected of being in the prepupal stage were transferred to individual containers wrapped in aluminium foil to isolate the developing pupae and emerging adults from sunlight.

\section{Study techniques}

Larvae were killed by boiling water and preserved in ethanol $(75 \%)$. For preparation of microscope slides, three larvae were decapitated, macerated in boiling $10 \%$ $\mathrm{KOH}$, rinsed in distilled water, and placed in lactic acid for subsequent preparation and mounting of mouthparts and sensory structures on temporary microscope slides.

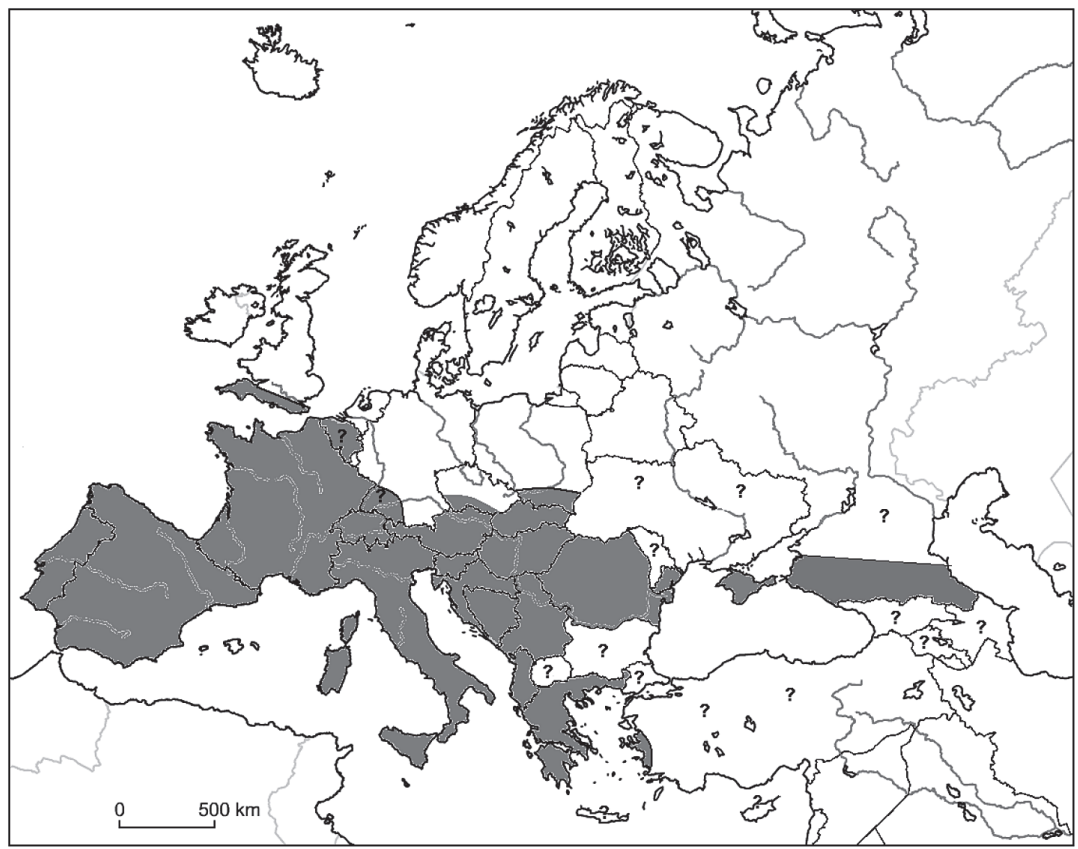

Fig. 1. Distribution map of Astrapaeus ulmi (? - occurrence needs confirmation or precise limits unclear). 
Habitus illustrations of egg, larvae, pupae, adult, as well as selected larval, and all pupal morphological structures were traced from photos taken by a digital camera mounted to a binocular compound microscope: Olympus ${ }^{\circledR}$ BX61 or SZX16 (Figs 2A, C-J; 3C-F, I-K, M-P; 4B-E, G-I, K-N; 5C; 6C, G; 7E; 8B, D, E; 9C, F; 10D, E, G, I, J; 11A-N; 12A-E; S1D, E; S2D, E; S3D-F; S4C, D, F). The final image adjustments were made by using CorelDraw Graphics Suite X5. Microstructure of the egg, some structure of larvae and types of larval setae was documented using SEM, type VEGA3 TESCAN (Figs 2B, 13A-K, 14A-O). For the SEM work, larval specimens taken from alcohol were briefly dried and placed directly in the SEM chamber for observation. Other larval morphological structures were drawn using light microscopy and a camera lucida. Microstructure of some pupal segments, protuberances on tibiae and gonotheca were studied from fragments of exuviae. The colour descriptions were based on freshly killed specimens.

\section{Measurements and their abbreviations}

Measurements of larvae and pupae were made by Stream Motion 1.7 software or calibrated eyepiece linear micrometre, and given in millimetres or micrometres as explained in Pietrykowska-Tudruj and Staniec (2012). Terminology of morphological structures and their abbreviations generally follows Solodovnikov (2005) with modifications clearly seen in the present figures. The terminology of chaetotaxy (selected aspects only) mainly follows Ashe and Watrous (1984), Schmidt (1996), Staniec et al. (2011) and Solodovnikov (2007). Material examined for morphological descriptions includes 15 eggs, 8 first instar larvae $\left(\mathrm{L}_{1}\right), 10$ third instar larvae $\left(\mathrm{L}_{3}\right)$, and 8 pupae. The second instar larvae $\left(\mathrm{L}_{2}\right)$ share most of the important characters with $\mathrm{L}_{3}$ and only slightly differ from the latter. Therefore, they were not described. Voucher specimens are deposited in the collections of the Department of Zoology, Marie Curie Sklodovska University. Material used for the study of Astrapaeus biology includes 52 eggs, $29 \mathrm{~L}_{1}, 21 \mathrm{~L}_{2}, 10$ $\mathrm{L}_{3}, 9$ prepupae, and 3 pupae.

\section{Results}

\section{Phylogenetic relationships of Astrapaeus based on adult morphology}

Within the tribe Staphylinini, Astrapaeus was considered a member of the subtribe Quediina for a long time
(Herman, 2001) due to its Quedius-like habitus. Recent phylogenetic research on Staphylinini has led to a more restrictive concept of the subtribe Quediina (review in Solodovnikov, 2012). In particular, two phylogenetic analyses based on adult morphology of recent taxa (Solodovnikov, 2006; Solodovnikov and Schomann, 2009) resolved the genus Astrapaeus as a basal lineage of Staphylinini with somewhat uncertain sister relationships, but definitely not even closely related to Quediina. Parisanopus, Bolitogyrus, Lonia, Quediomacrus or Antimerus appeared as presumably more or less closely related to Astrapaeus in the equally most parsimonious phylogenetic trees. Analysis that involved morphologies of recent and fossil taxa of Staphylininae (Solodovnikov et al., 2013) also placed Astrapaeus remotely from the subtribe Quediina, at the base of Staphylinini and as a lineage sister to the type species of the extinct genus Cretoquedius. Finally, the latest analysis based on the adult morphology of recent taxa (Brunke and Solodovnikov, 2013) confirmed the basal position of Astrapaeus and demonstrated a close affinity to Parisanopus and the subgenus Quedius (Cyrtoquedius). Parisanopus is a monotypic Neotropical genus, while Cyrtoquedius includes a group of poorly known species, also restricted to the Neotropics, and currently has the misleading status of a subgenus of the genus Quedius.

In summary, Astrapaeus appears to be a relatively old, presumably relict lineage of Staphylinini, based on adult morphology, the hitherto only available source of phylogenetic data for this genus. This conclusion seems to be supported by paleontological and biogeographic evidence: although Astrapaeus is now restricted to Europe in distribution, it was the sister group to an extinct lineage known from the Mid Cretaceous of Eastern Asia (Solodovnikov et al., 2013) and also has extant relatives from the Neotropics (Brunke and Solodovnikov, 2013).

Taxonomy, distribution, and bionomics of Astrapaeus ulmi

Astrapaeus is a monotypic genus of the tribe Staphylinini, established by Gravenhorst (1802) for Staphylinus ulmi Rossi, 1790 (Figs 12A-E). Synonymy and summary of literature on the species can be found in Herman (2001), while the latest diagnostic information was provided in Assing and Schülke (2012).

Astrapaeus ulmi is broadly distributed in Europe except its northern part, and reaches western Turkey (Fig. 1). However, its occurrence within this distribution is patchy 
A
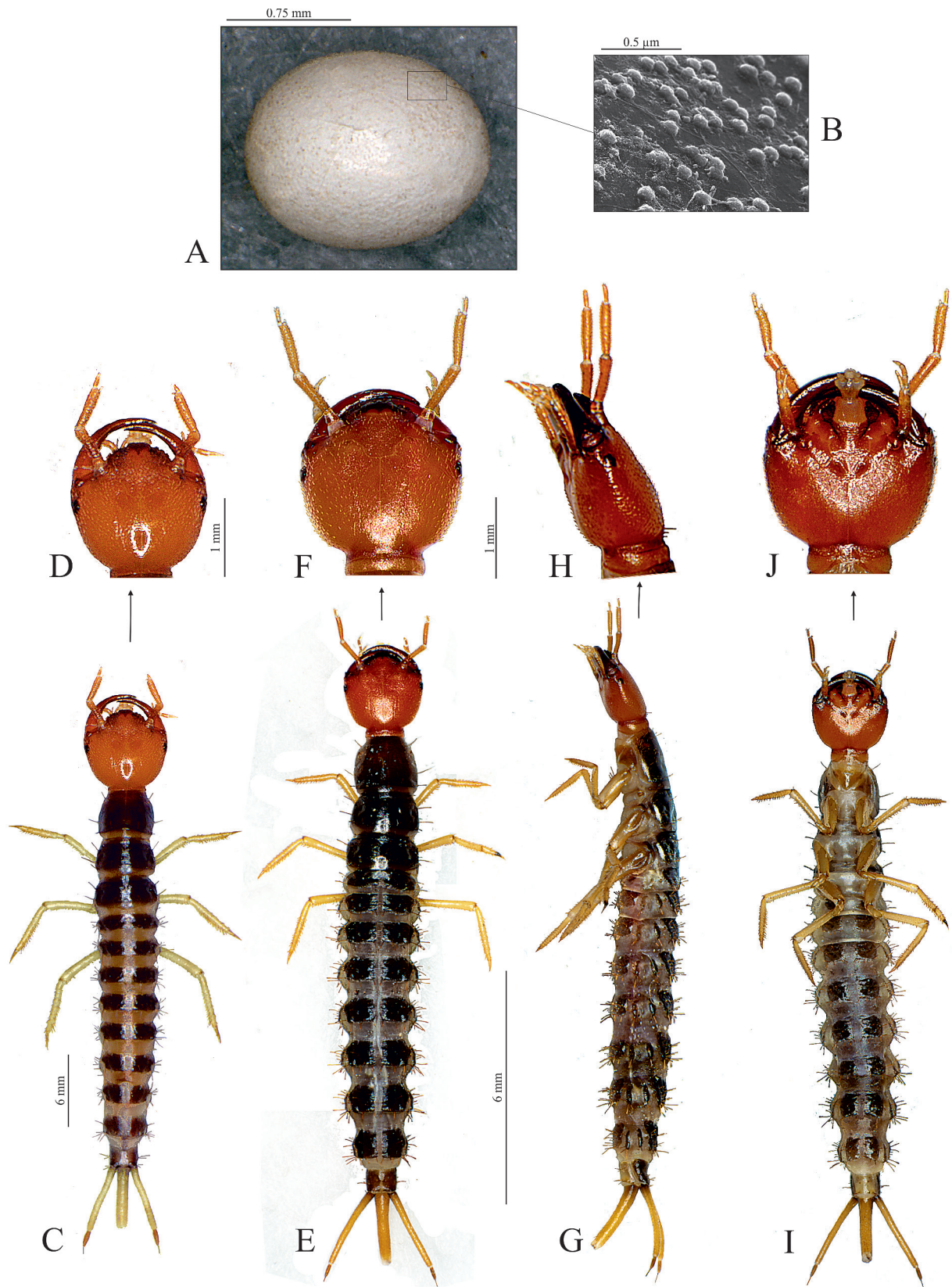

Fig. 2. Astrapaeus ulmi, egg (A, B), $1^{\text {st }}$ larval instar (C, D), mature larva (E-J). A, B, general view with microstructure (B); C-J, general habitus with head, dorsal $(\mathrm{C}-\mathrm{F})$ lateral $(\mathrm{G}, \mathrm{H})$ and ventral $(\mathrm{I}, \mathrm{J})$ views.

and it is generally considered a rare species (Assing and Schülke, 2012). Some early opinions on the ecological requirements of A. ulmi that suggested an association with old, hollow trees or decayed wood were probably erroneous (Horion, 1965; Kreissl, 1987). Many authors have collected the adults at open grassy sites with some layer of humus, under heaps of rotting plants or stones, and often in riverside areas covered with low vegetation (Smetana, 1958; Fülöp, 2005; Stan, 2005; summary in Assing and Schülke, 2012). As a thermophilous species, A. ulmi inhabits xerothermic habitats with moderately moist soils near the northern limits of its range (Hance, 2007; Wojas, 2011). For example, at the Polish source locality for the present study, A. ulmi occurred in an 

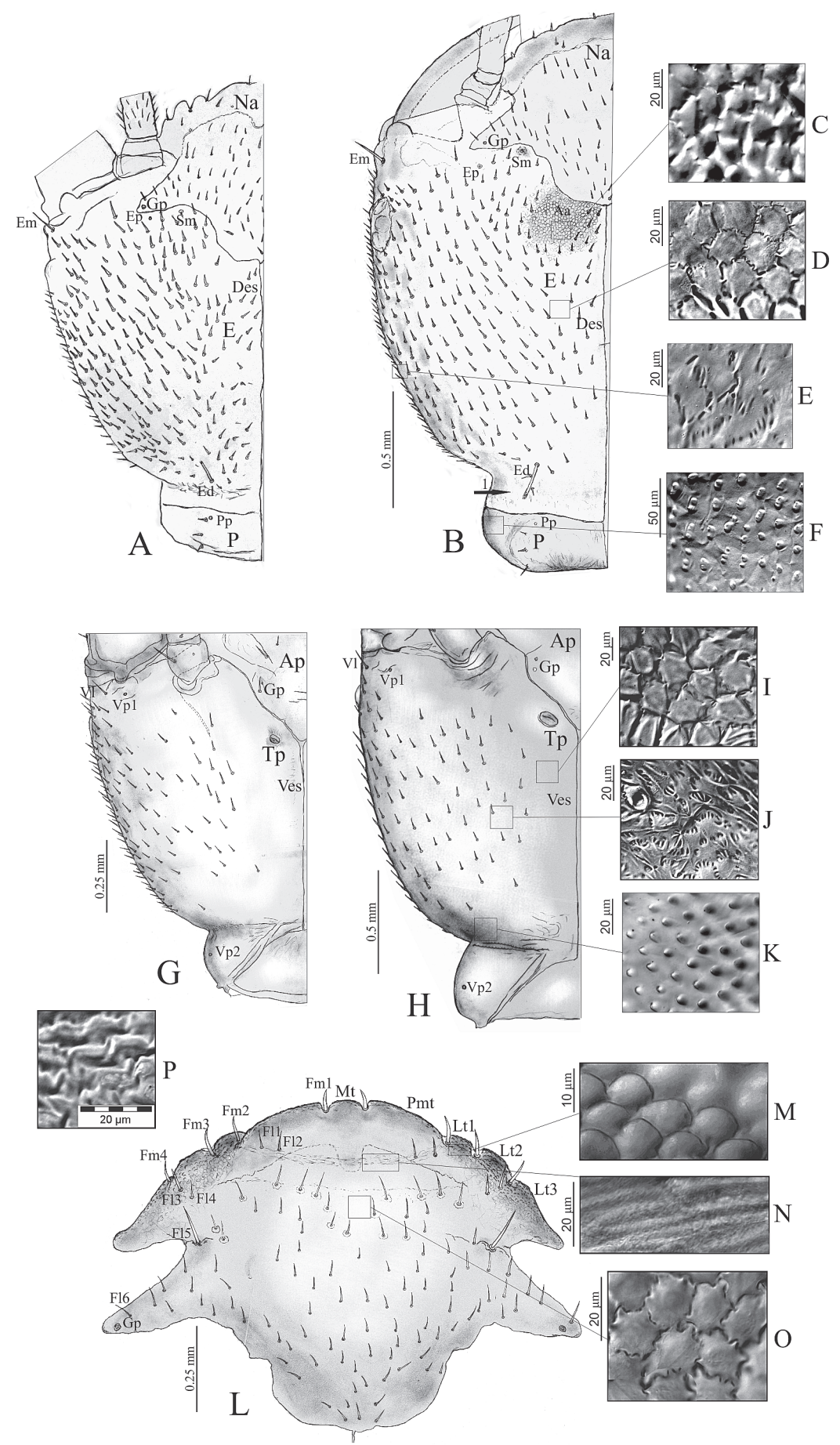

Fig. 3. Astrapaeus ulmi, $1^{\text {st }}$ larval instar (A, G, P), mature larva (B-F, H-O). A, B, head, left side, dorsal; C-F, microstructure of dorsal surface of head; G, H, head, left side, ventral; I-K, microstructure of ventral surface of head; L-P, nasale with microstructure (M-P). Abbreviations: Aa, anterior area; Ap, apotome; Des, dorsal ecdysial suture; E, epicranial part; Ed, epicranialodorsal seta; Em, epicranialomarginal seta; Ep, epicranial pore; Fl, frontal lateral seta; Fm, frontal marginal seta; Gp, glandular pit; Lt, lateral teeth; Mt, median tooth; Na, nasale; P, posterior part; Pmt, paramedian tooth; Pp, posterior pore; Sm, sensillum; Tp, tentorial pit; Ves, ventral ecdysial suture; Vl, ventralolateral seta; Vp, ventral pore. 


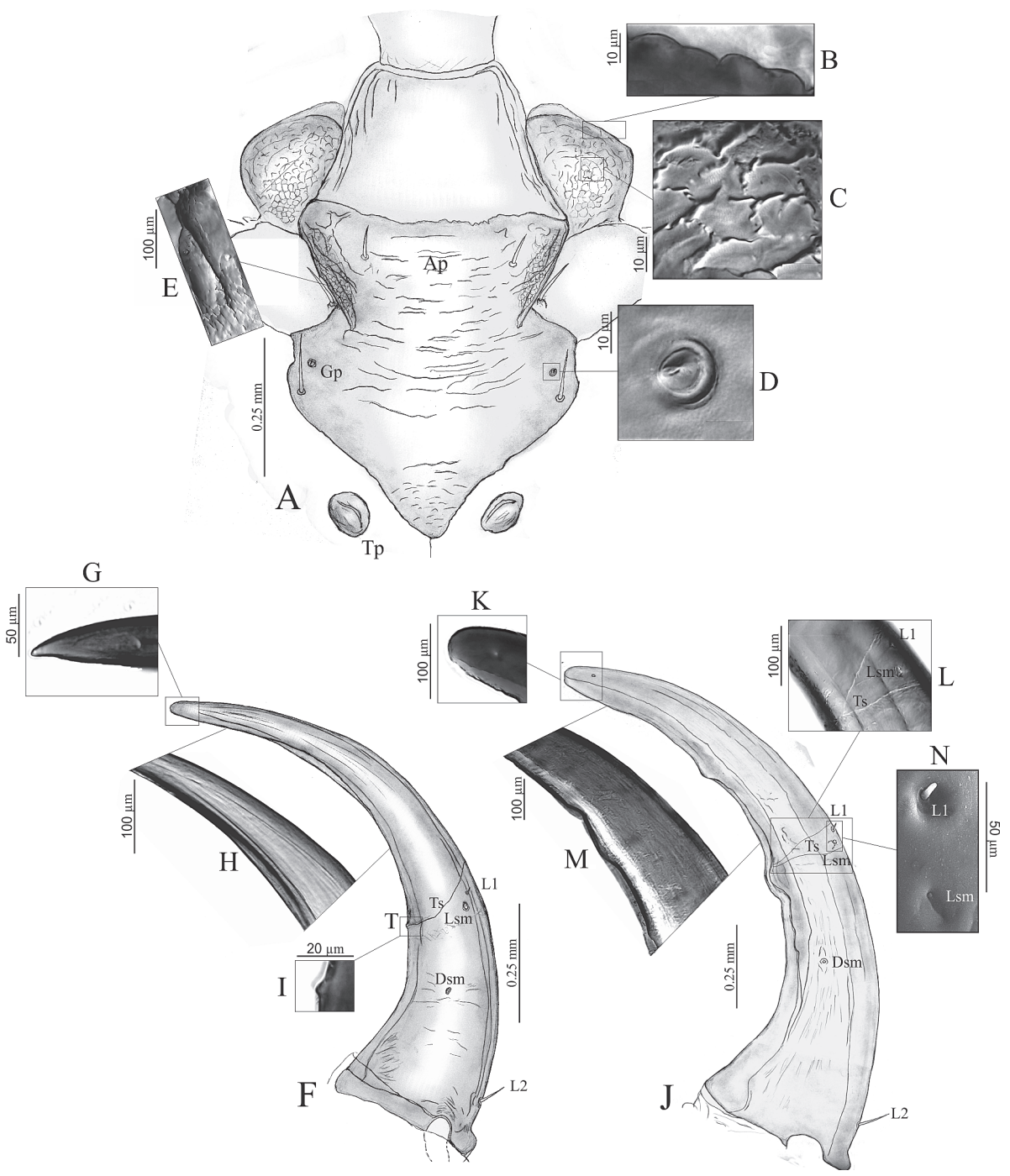

Fig. 4. Astrapaeus ulmi, $1^{\text {st }}$ larval instar (F-I), mature larva (A-E, J-N). A-E, apotome with microstructure (B, C, E) and glandular pit (D). F-N, right mandible, dorsal. G, K, apex of mandible. H, M, strengthen of inner margin of mandible; I, tooth; L, transverse sutures of mandible; N, lateral sensillum and setae. Abbreviations: Ap, apotome; Dsm, dorsal sensillum; Gp, glandular pit; L, lateral seta; Lsm, lateral sensillum; T, tooth; Tp, tentorial pit; Ts, transverse suture.

abandoned limestone quarry covered with ruderal and xerothermic plant communities with single trees and shrubs. This locality represents the northern most recorded site for A. ulmi. Numerous individuals occurred under stones, bricks, and among plant roots (Wojas, 2011). Nothing was previously known about other details of the biology of the species.

\section{Description of the immature stages}

Egg

Length: $1.82-1.99 \mathrm{~mm}$ (mean $1.89 \mathrm{~mm}$ ); width: 1.47 $1.60 \mathrm{~mm}$ (mean $1.55 \mathrm{~mm}$ ); colour white, shape oval (Fig. 2A); microstructure of the surface as in Fig. 2B. 


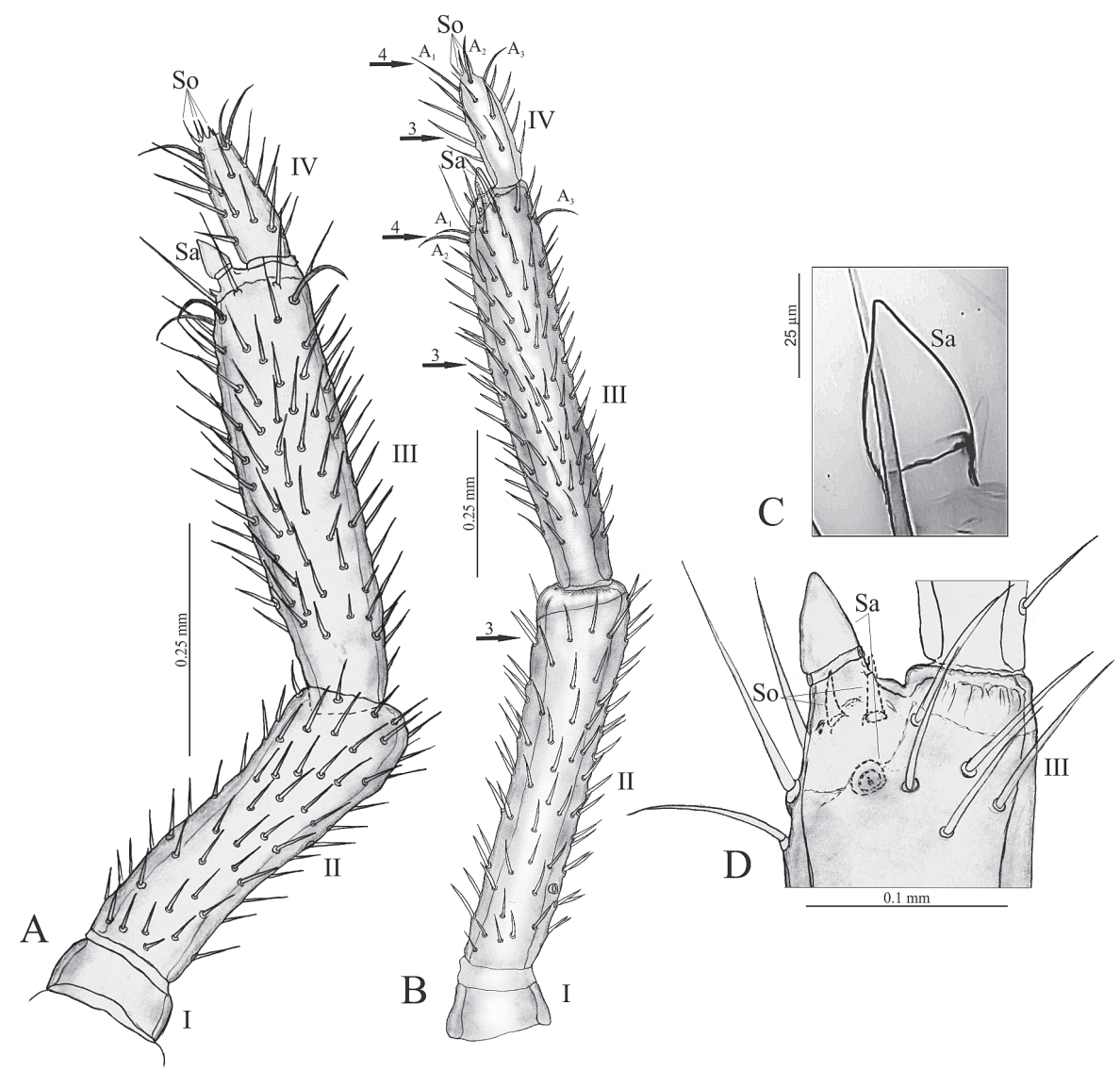

Fig. 5. Astrapaeus ulmi, $1^{\text {st }}$ larval instar (A, C), mature larva (B, D). A, B, right antenna, dorsal; C, sensory appendage; D, details of anterior part of third antennal segment. Abbreviations: I-IV, antennal segments; $\mathrm{A}_{1-3}$, seta; Sa, sensory appendages; So, solenidium.

Generic diagnosis of Astrapaeus based on the mature (third instar) larva

The combination of characters distinguishing the mature larvae of Astrapaeus from all genera within the tribe Staphylinini for which the larvae are known includes: 1) head capsule, antennae, legs, abdominal segment $X$, and segment I of the urogomphi with numerous short setae; 2) epicranium, thoracic tergites and coxae covered with club-shaped setae with multispinose apex; 3) ventral side of head capsule without long setae; 4) nasale with 9 teeth; 5) antenna with cone-shaped sensory appendage; 6) maxillary and labial palps 3- and 2-segmented, respectively; 7) stipes of maxilla with hair-like cuticular processes; 8) mala finger-shaped, more than 3.5 times as long as wide, with 2 spine-like setae; 9) foretibia with numerous scattered bifid setae; 10) tarsungulus with 3 spines; 11) urogomphi longer than pygopod; 12) segment II of urogomphus with macro- trichiae; 13) apical seta of urogomphus club-shaped with multispinose apex. Of these, the characters of Astrapaeus unique within tribe Staphylinini are listed in Table 2.

Mature larva (third instar) (habitus as on Figs 2E-J) Measurements as in Table S1. Body of contrasting coloration pattern: head dark ginger; antennae, maxillae, labium and legs yellowish-brown; thoracic, and abdominal tergites I-VIII dark brown; abdominal pleurites and sternites distinctly paler than tergites; abdominal segments IX and X brown and yellow, respectively; urogomphi yellow with second segment darker. Body cylindrical, head wider than thorax, legs slender, first abdominal segment I narrower than segment II, segments II and III, each, about as wide as long, urogomphi longer than pygopod (Figs 2G, I). Chaetotaxy: numerous club-shaped setae with multispinose apex scattered 


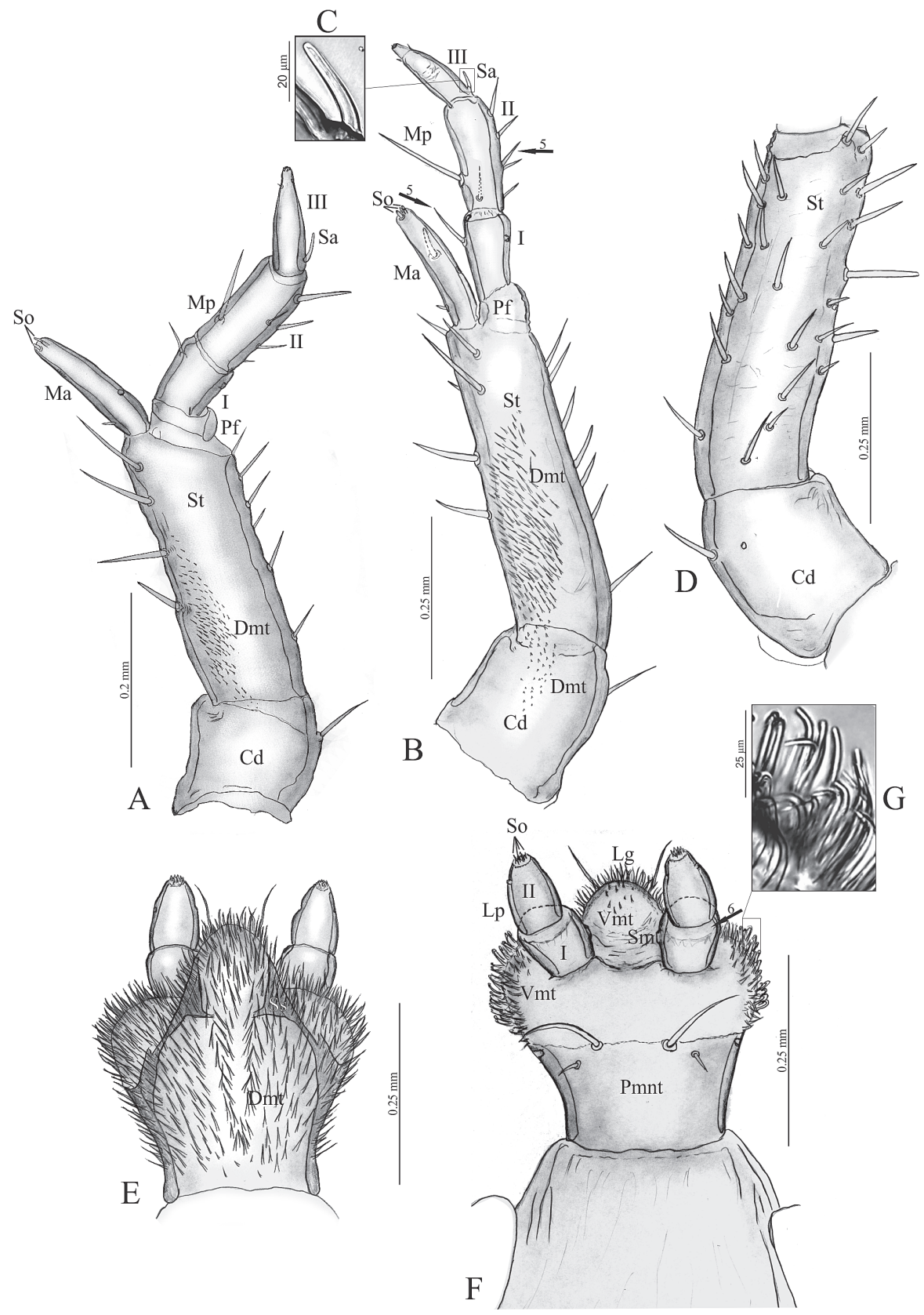

Fig. 6. Astrapaeus ulmi, $1^{\text {st }}$ larval instar (A), mature larva (B-G). A-C, right maxilla, dorsal with sensory appendage (C); D, right stipes and cardo, ventral; E, hypopharynx, dorsal; F, G, labium, ventral with microtrichia (G). Abbreviations: I-IV, segments of maxillary or labial palps; Cd, cardo; Dmt, dorsal microtrichia; Lg, ligula; Lp, labial palp; Ma, mala; Mp, maxillary palp; Pf, palpifer; Pmnt, prementum; Sa, sensory appendage; Sm, sensillum; So, solenidium; Ss, sclerotized strip; St, stipes; Vmt, ventral microtrichia.

over the entire body including head (Figs 14I, L); numerous spine-like setae on legs and some on the nasale and maxillae (Figs 13B, C, 14B): club- and fan-shaped setae on pronotum (Figs 13I, 14G, O), spear-shaped and bifurcate setae on the legs (Figs 13H, 14E, F), simple setae (Fig. 14A) also scattered over the entire body.

Head (Figs 2E-J; 3B-F, H-O; 4A-E, J-N, 5B, D; 6BG; S1A-C, E, G, H; S2B-G): about as wide as long, 


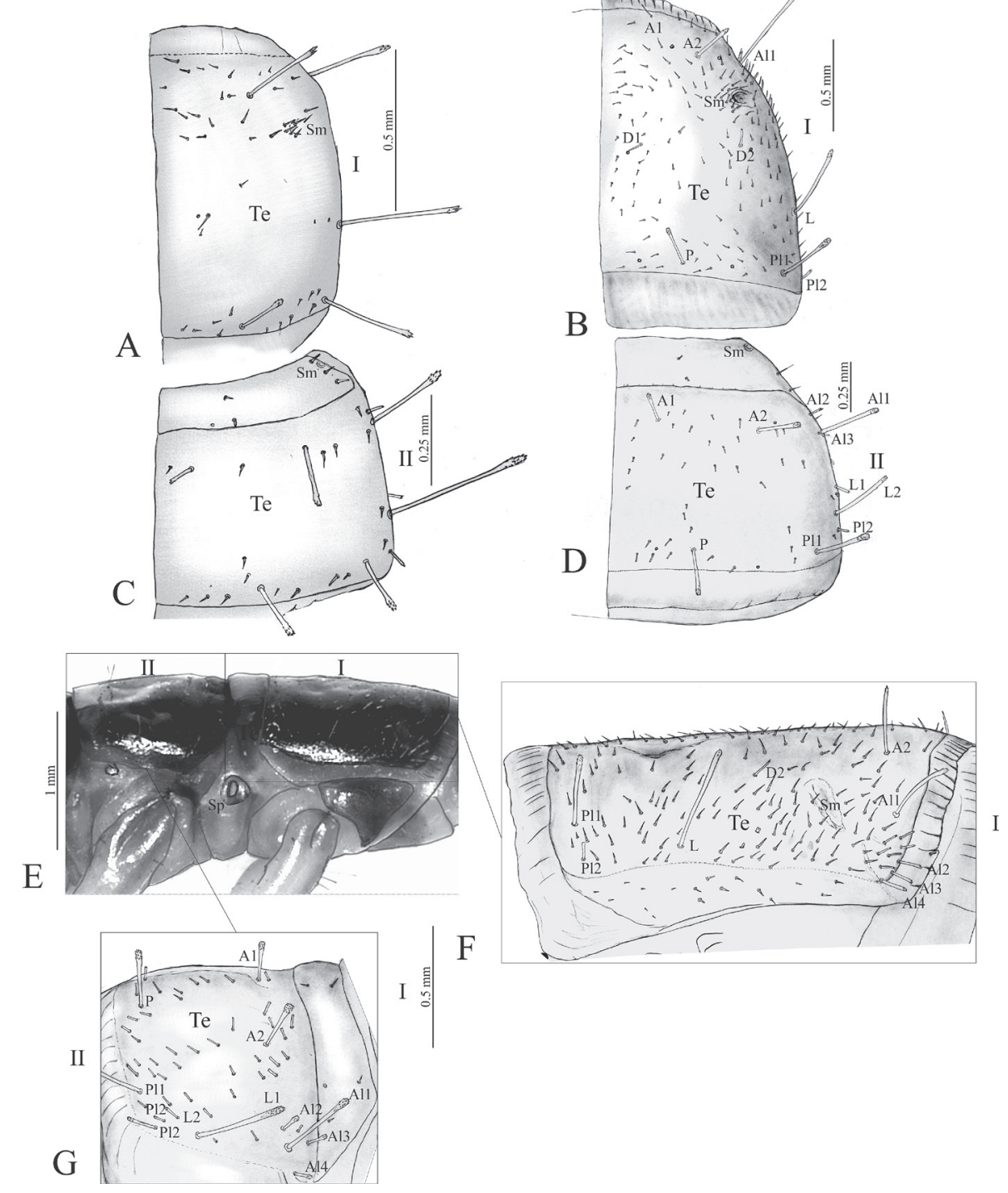

Fig. 7. Astrapaeus ulmi, $1^{\text {st }}$ larval instar (A, C), mature larva (B, D-G). A, B, right half of pronotum, dorsal; C, D, right half of mesonotum, dorsal;. E-G, right side of prothorax (I) and mesothorax (II), lateral; F, right side of pronotum, lateral; G, right side of mesonotum, lateral. Abbreviations: A, anterior seta; Al, anterolateral seta; D, dorsal seta; L, lateral seta; P, posterior seta; Pl, posterolateral seta; Sm, sensillum; Sp, spiracle; Te, tergite.

widest at the level of stemmata (Fig. 3B). Epicranial part (E) with 2 pairs of symmetrically located setae (Fig. $14 \mathrm{~K}$ ) and numerous short, scattered setae; areas with peculiar microstructure free of setae (Aa) as on Figs 3B-C,13A; posterior part $(\mathrm{P})$ as on Fig. 3B. Four pairs of stemmata (Fig. S1A). Nasale (Na) (Figs 3L, 13B-C) with 9 teeth, at least 10 pairs of setae located symmetrically (Fm1-4, Fl1-6). Ventral side of head with 1 pair of medium long and numerous short, scattered setae (Fig. 3H). Apotome (Ap) as in Figs 4A-E. Mandibles (Figs 4J-N, S1G-H) symmetrical, slender; anterior part of inner margin enforced (Fig. 4JM). Antennae 4-segmented (Figs 5B, D, S2B-E), length ratio of segments I-IV $=1.0: 8.2: 8.6: 2.5$, respectively; segment I twice as wide as long; segment II 4.2 times as long as wide; segment III 5.1 times as long as wide with 2 sensory appendages (Sa) and solenidia (So); segment IV about 3 times as long as wide and 3.5 times as long 

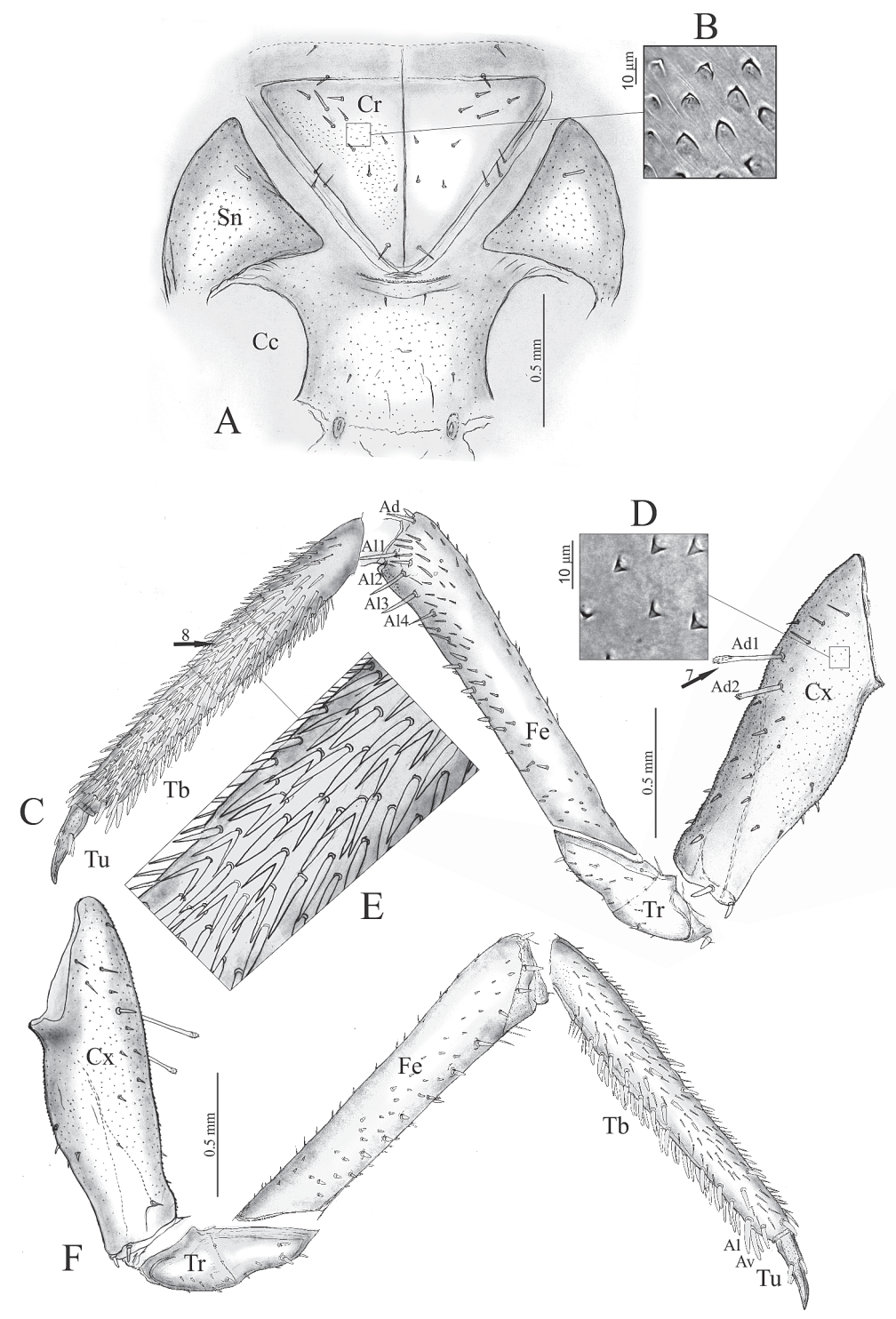

Fig. 8. Astrapaeus ulmi, mature larva. A, B, prothorax, ventral with microstructure of cervicosternum (B); C, segments of fore leg, anterior; $\mathrm{D}$, microstructure of coxa; $\mathrm{E}$, details of setae on tibia; $\mathrm{F}$, segments of fore leg, posterior. Abbreviations: Ad, anterodorsal seta; $\mathrm{Al}$, anterolateral seta; Av, anteroventral seta; Cc, coxal cavity; Cr, cervicosternum; Cx, coxa; Fe, femur; Sn, sternite; Tb, tibia; Tr, trochanter; Tu, tarsungulus; V, ventral seta.

as cone-shaped sensory appendage of segment III (Figs 5B, S2E, S2C). Epipharynx as on Fig. 13D. Maxillae (Figs 6B-D, S2F, G, 13E, G): length ratio of cardo (Cd) : $\operatorname{stipes}(\mathrm{Stp})=1: 2.1$, respectively; cardo as long as wide, dorso-anterior part with microtrichia; stipes rectangular 3.3 times as long as wide with 25 setae, 1 pore and region of microtrichia (Dmt) (Fig. 13G). Mala (Ma) (Figs 6B, S2F, G, 13E): long, finger-shaped, with 2 setae, 3 short sensory appendages apically and pores; length ratio of mala: segment I of maxillary palp $=1.5: 1$, respectively. Maxillary palp (Pm) 3-segmented; length ratio of segments I-III = 1:1.4:1, respectively; segments I, II, III 1.6, 2.4, 3.3 times as long as wide, respectively; chaetotaxy as in Figs 6B, S2F. Hypopharynx with sclerotized stripes (Ss) and dorsal microtrichia (Dmt) (Fig. 6E). Labium (Figs 6F, G, 13F): ligula domed, distinctly wider at the base than segment I of labial palp, with 2 setae and microtrichia (Vmt). Labial 


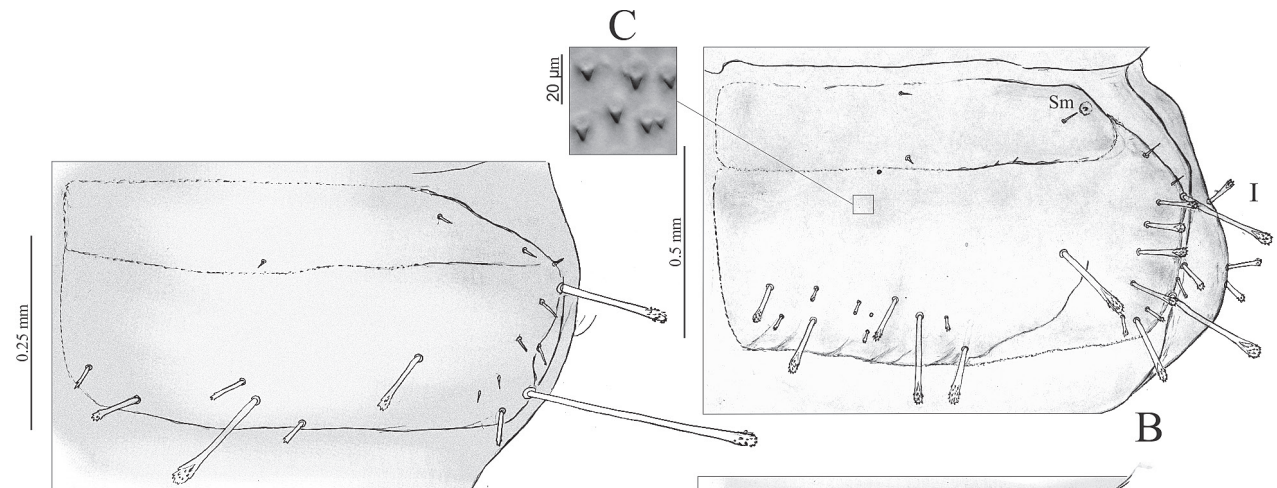

\section{A}
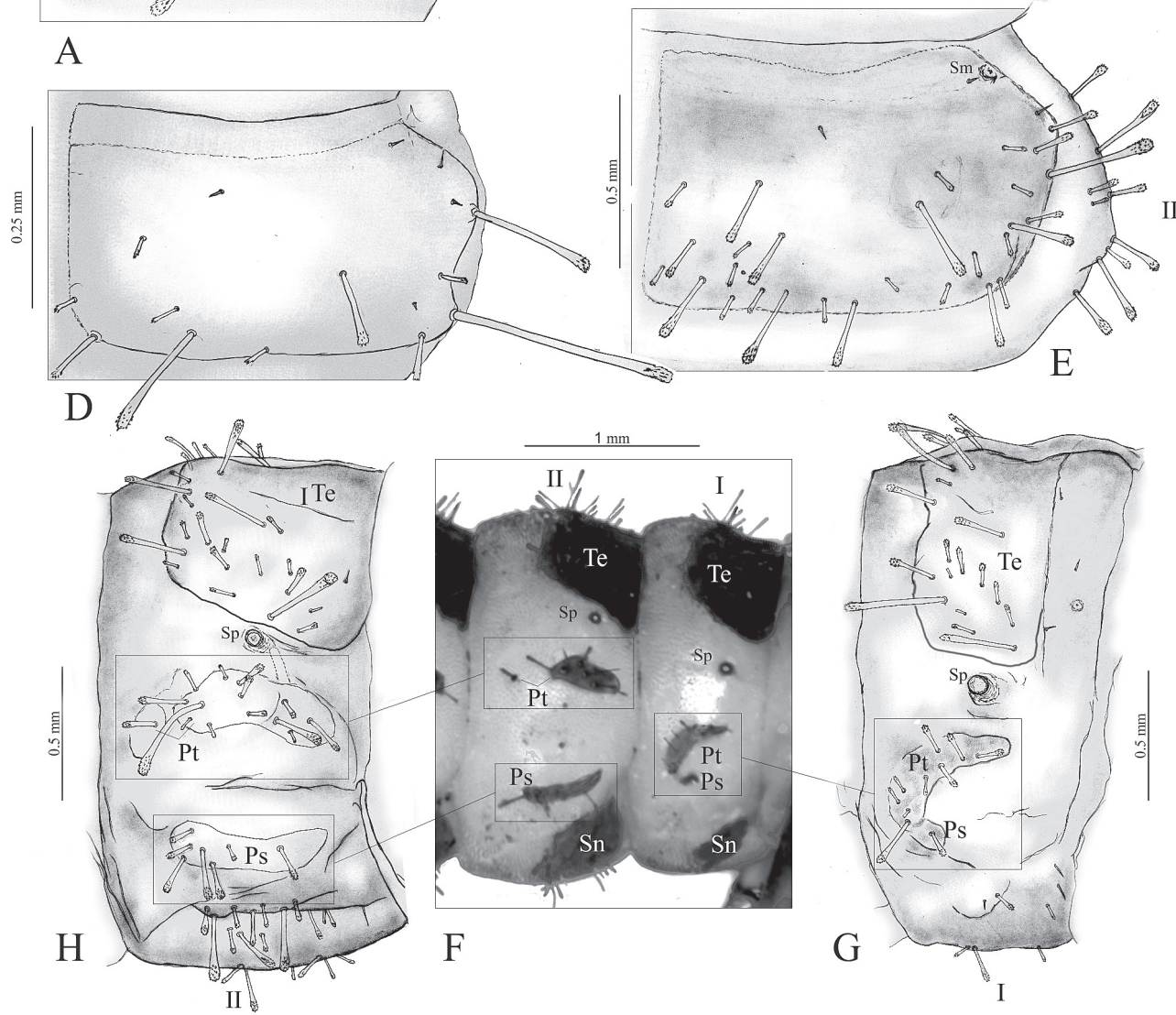

$\mathrm{F}$

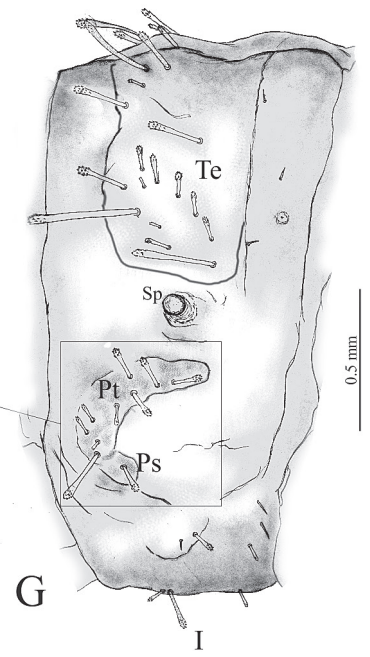

Fig. 9. Astrapaeus ulmi, $1^{\text {st }}$ larval instar (A, D), mature larva (B, C, E-H). A, B, right abdominal tergites I, dorsal; C, microstructure of abdominal tergites I; D, E, right abdominal tergites II, dorsal; F-H, right side of abdominal segments I (G) and II (H), lateral. Abbreviations: Ps, parasternite; Pt, paratergite; Sm, sensillum; Sp, spiracle; St, sternite; Te, tergite.

palp (Lp); stout, length ratio of segments I and II = 1.2:1, respectively; segment I short, $1.2 \times$ as wide as long; segment II cone-shaped, $1.3 \times$ as long as wide, tapered subapical with solenidia (Fig. 13F).

Thorax (Figs 7B, D-G, 8A-F, S3B, C-G, 13H, I). Leg 5-segmented, long. Length ratio of procoxa :-trochanter $:$-femur : -tibia : -tarsungulus $=4.1: 1.9: 5.5: 4.7: 1$, respec- tively. Foreleg (Figs 8C-F, Fig. 14G): coxa (Cx) with 2 long, club-shaped with multispinose apex dorsally (Ad1, $\mathrm{Ad} 2$ ) and numerous distinctly shorter setae; femur $(\mathrm{Fe})$ with numerous setae: spine-shaped (Ad, Al1-4), spearshaped, and simple (Fig. 14B); tibia (Tb) extremely densely pubescent, anterior part with numerous spineshaped and -bifurcate setae scattered on all the surface 
Table 1. Comparison of the mature larvae of Astrapaeus ulmi with other known larvae of Staphylinini $(1=$ Abemus chloropterus, $2=$ Acylophorus wagenschieberi, $3=$ Anaquedius vernix, $4=$ Atanygnathus bicolor, $5=$ A.terminalis, $6=$ Antimerus punctipennis, $7=$ Bisnius nitidulus, 8 = Cafius xantholoma, $9=$ Creophilus maxillosus, $10=$ Dinothenarus pubescens, $11=$ Emus hirtus, $12=$ Erichsonius spp., $13=$ Euryporus picipes, $14=$ Gabrius spp., $15=$ Hesperus rufipennis, $16=$ Korgella caucasica, $17=$ Natalignathus olgae, $18=$ Neobisnius spp., $19=$ Nordus fungicola, $20=$ Ocypus spp., $21=$ O. fulvipennis, $22=$ O. nitens, $23=$ Ontholestes tesselatus, $24=$ Philonthus spp., $25=$ Platydracus spp., 26 $=P$. latebricola, $27=P$. tomentosus, $28=$ Quedius spp. (excluding $Q$. antipodum), $29=Q$. antipodum, $30=Q$. brevicornis, $31=Q$. brevis, 32 $=Q$. cruentus, $33=Q$. dilatatus, $34=Q$. fuliginosus, $35=Q$. microps, $36=$ Rabigus tenuis, $37=$ Sedolinus quediosimilis, $38=$ Staphylinus erythropterus, 39 = Tasgius pedator). AMBLYOP = Amblyopinina; PHILONT = Philonthina; QUED = Quediina; STAPH = Staphylinina; TANYGN = Tanygnathinina; XANTHOP = Xanthopygina; $\mathrm{S}=$ column with taxa having respective character states same as in $A$. ulmi; $\mathrm{D}=$ column with taxa having respective character states different from A. ulmi; number in square brackets $[\mathrm{N}]=$ total number of characters either

Character states found in Astrapaeu $\quad$ subtribe incertae sedis $\quad$ QUED

$2,3,13,28,30-35$

S[17]

1) Head capsule with club-shaped

6
setae with multi spinose apex

2) Head capsule with irregular short setation

3) Epicranial gland present

6

4) Nasale with nine teeth

6,16

6,37

$6,16,37$

6) Ventral ecdysial lines Y-shaped

7) Stipes of maxillae with microtrichiae 6

8) Mala of maxillae elongate (longer than any palpal segment)

9) Ligula unsclerotised

6

16

6

6 segment

11) Maxillary and labial palps threeand two-segmented, respectively

12) Hypopharynx with microtrichiae distributed on its entire surface

13) Neck narrow (at most $1 / 2$ as wide as head)

14) Thorax with club-shaped setae with multispinose apex

15) Meso- and metanotum with long club- 6 shaped setae with multispinose apex

16) Foretibia with bifurcate setae

16

$6,16,37$

6

6

6

6

37

37

$\mathrm{D}[16]$

$\mathrm{S}[13]$

16,37

37

37

16

16,37

$-$

2,28

16,37

$-$

2


Table 1 Cont. shared or different, respectively, among A. ulmi and a given subtribe. Characters for some species were extracted from their respective descriptions as follows: Acylophorus wagenschieberi (Staniec, 2005a), Anaquedius vernix (LeSage, 1984), Atanygnathus bicolour (Solodovnikov, 2005), A. terminalis (Staniec, 2005b), Antimerus punctipennis (Solodovnikov and Newton, 2010), Bisnius nitidulus (Staniec and Pietrykowska-Tudruj, 2010), Creophilus maxillosus (Dajoz and Caussanel, 1968), Erichsonius spp (Schmidt, 1996; Pietrykowska-Tudruj and Staniec, unpublished data), Hesperus rufipennis (Staniec, 2004), Korgella caucasica (Gusarov and Koval, 2002), Natalignathus olgae (Solodovnikov, 2005), Neobisnius spp. (e.g. Schmidt, 1994), Nordus fungicola (Chatzimanolis, 2004), Ocypus fulvipennis (Staniec et al., 2009), Philonthus spp. (e.g. Staniec and Pietrykowska-Tudruj, 2007), Platydracus latebricola (Pietrykowska-Tudruj and Staniec, 2012), P. tomentosus (Schmidt, 1994), Quedius antipodum (Pietrykowska-Tudruj et al., 2012), Q. brevicornis (Staniec, 2003), Rabigus tenuis (Staniec and Pietrykowska-Tudruj, 2009), Sedolinus quediosimilis (Solodovnikov, 2006), Staphylinus erythropterus (Pietrykowska-Tudruj and Staniec, 2012), Tasgius pedator (Pototskaya, 1967).

\begin{tabular}{|c|c|c|c|c|c|c|c|}
\hline \multicolumn{2}{|c|}{$\begin{array}{l}\text { PHILONT } \\
7,8,12,14,15,18,24,36\end{array}$} & \multicolumn{2}{|l|}{$\begin{array}{l}\text { AMBLYOP } \\
17,29\end{array}$} & \multicolumn{2}{|l|}{$\begin{array}{l}\text { TANYGN } \\
4,5\end{array}$} & \multicolumn{2}{|l|}{$\begin{array}{l}\text { XANTHOP } \\
19\end{array}$} \\
\hline S[6] & $\mathrm{D}[18]$ & $\mathrm{S}[5]$ & $\mathrm{D}[18]$ & $\mathrm{S}[3]$ & $\mathrm{D}[16]$ & $S[3]$ & $\mathrm{D}[11]$ \\
\hline- & $\begin{array}{l}7,8,12,14 \\
15,18,24,36\end{array}$ & - & 17,29 & - & 4,5 & - & 19 \\
\hline- & $\begin{array}{l}7,8,12,14 \\
15,18,24,36\end{array}$ & - & 17,29 & - & 4,5 & - & 19 \\
\hline $\begin{array}{l}7,12,15 \\
18,24,36\end{array}$ & - & 29 & 17 & - & 4,5 & 19 & - \\
\hline $\begin{array}{l}7,8,12,15 \\
18,24,36\end{array}$ & 14 & 17,29 & - & 4,5 & - & - & 19 \\
\hline 12,18 & $8,15,24,36$ & - & 17,29 & 4,5 & - & - & 19 \\
\hline $\begin{array}{l}7,8,12,14 \\
15,18,24,36\end{array}$ & - & 29 & 17 & - & 4,5 & - & - \\
\hline $7,12,14,15$ & $8,18,24,36$ & 29 & - & - & 4,5 & 19 & - \\
\hline- & $\begin{array}{l}7,8,12,14, \\
15,18,24,36\end{array}$ & - & 17,29 & - & 4,5 & - & - \\
\hline- & $\begin{array}{l}7,12,14,15 \\
18,24,36\end{array}$ & - & 17,29 & - & 4,5 & - & - \\
\hline- & $\begin{array}{l}7,12,14,15 \\
18,24,36\end{array}$ & - & 17,29 & - & 4,5 & - & - \\
\hline - & $\begin{array}{l}7,8,12,14 \\
15,18,24,36\end{array}$ & - & 17,29 & - & 4,5 & - & 19 \\
\hline - & $\begin{array}{l}7,8,12,15 \\
18,24,36\end{array}$ & - & 29 & - & 4,5 & - & - \\
\hline- & $\begin{array}{l}7,8,12,14 \\
15,18,24,36\end{array}$ & - & 17,29 & - & 4,5 & - & 19 \\
\hline- & $\begin{array}{l}7,12,15,18 \\
24,36\end{array}$ & - & 17,29 & - & 4,5 & - & 19 \\
\hline - & $\begin{array}{l}7,12,15,18 \\
24,36\end{array}$ & - & 17,29 & - & 4,5 & - & 19 \\
\hline 12 & $\begin{array}{l}7,8,14,15 \\
18,24,36\end{array}$ & 29 & 17 & - & 4,5 & - & 19 \\
\hline- & 12 & - & 29 & - & - & - & - \\
\hline- & $\begin{array}{l}7,8,12,14 \\
15,18,24,36\end{array}$ & - & 17,29 & - & 4,5 & - & 19 \\
\hline- & $\begin{array}{l}7,8,12,14 \\
15,18,24,36\end{array}$ & - & 17,29 & - & 4,5 & - & 19 \\
\hline- & $\begin{array}{l}7,8,12,14 \\
15,18,24,36\end{array}$ & - & 17,29 & - & 4,5 & - & 19 \\
\hline
\end{tabular}


Table 2. Larval characters of Astrapaeus ulmi unique within tribe Staphylinini (marked by arrows in Figs 3B, 5B, 6B, F, 8C, 10H, S2D, E, S3G).

\begin{tabular}{llll}
\hline \multicolumn{1}{c}{ characters } & Astrapaeus ulmi & other members of Staphylinini \\
\hline 1 & $\begin{array}{l}\text { Number of long or intermediate-size setae on dorsal } \\
\text { side of epicranium }\end{array}$ & 1 (Fig. 3B) & $>1$ \\
2 & Apotome, shape & differ in the shape and chaetotaxy (Fig. 4A) & sparse or absent \\
3 & Short setae on antennal segments II-IV & dense (Fig. 5B) & long or absent \\
4 & Setae (A A $_{1-3}$ ) on antennal segment III and IV & short (Figs 5B, S2D, E) & 0 and 2, respectively \\
5 & Number of setae on segment I and II of maxillary palp & 1 and 7, respectively (Fig. 6B) & elongated \\
6 & Basal segment of labial palp & transverse & absent \\
7 & Club-shaped setae (Ad) with multispinose apex on & present (Figs 8C, 14G) & scarcer \\
& anterior coxa & extremely dense (Figs 8C, E, 13H) & absent \\
8 & Arrangement of setae on foretibia & present (Figs S3G, 14F) & several \\
9 & Spear-shaped setae on tibia & absent \\
10 & Macrosetae on segment I of urogomphus & present (Figs 10H, 13J, K) & \\
11 Macrotrichia (Mat) on segment II of urogomphus & & \\
\hline
\end{tabular}

(Figs $8 \mathrm{C}, 13 \mathrm{H}$ ), posterior part with numerous spine-shaped and simple setae (Fig. 8F). Mid and hind legs longer than foreleg (Fig. S3G). Mid and hind legs with setae smaller than on foreleg and without bifurcate setae, with numerous, long, spear-shaped setae on ventral surface (Figs S3G, $14 \mathrm{~F}, \mathrm{H})$. Chaetotaxy of pronotum with 12 pairs of long or intermediate-size club-shaped setae with multispinose apex (A1, 2, Al1-4, D1 , 2, L, P, P11, 2); first pair of sensilla on pronotum in a deep cavity and surrounded by club- and fun-shaped setae (Figs 13I, 14M-O). Mesonotum as on Fig. 7D, with 11 pairs of long or intermediate-size club-shaped setae with multispinose apex. Chaetotaxy of meta- similar to mesonotum (Fig. S3B). Cervicosternum (Cr) triangular, setae as on Fig. 8A.

Abdomen (Figs 9B, C, E-H, 10C-M, S4A-D, F-I, 13J, K): segments I-VIII each with tergite (Te) and sternite $(\mathrm{St})$, a pair of paratergites $(\mathrm{Pt})$ and parasternites (Ps) laterally (Figs 9B, C, E-H). Segment I: tergite with 20 pairs of long or intermediate-size club-shaped setae with multispinose apex and 5 pairs of simple, micro setae anteriorly; sternite with 12 pairs of setae (Fig. S4A); each paratergite and -sternite with 9 and 1 clubshaped setae with multispinose apex, respectively (Figs 9F, G). Segments II-VIII (Figs 9E, F, H, S4B): tergites with 28 pairs of club-shaped setae with multispinose apex and 3 pairs of simple setae; sternites with 17 pairs of club-shaped setae with multispinose apex and a pair of simple (Fig. S4B); paratergites divided in 2 sclerites; parasternites with 7-12 club-shaped setae with multispinose apex. Setae on segment IX (Figs 10C, K) mostly club-shaped with multispinose apex. Segment I of urogomphi (Figs 10H, M, S4C, D, I) slender: the length to width ratio 10.8. Segment II of urogomphi (Figs 86J, K): the length to width ratio 3 . The ratio length of segment I: II of urogomphus $=7.8: 1$, respectively. Pygopod (Figs 10, F, L, S4C, D, F, H) slender, the ratio length to width 4 . Urogomphi longer than pygopod; length ratio of segments $\mathrm{X}$ : segment I : II of urogomphus : apical seta $=7.3: 9.3: 1.2: 1$, respectively.

First instar larva $\left(L_{1}\right)$ (only characters that differ from the mature larva; larval habitus as on Figs $2 C, D$ )

Measurements of the body as in Table S1. Colour: mandible divided by transversal suture (Ts) on 2 different coloured parts: darker anterior and lighter posterior, thoracic and abdominal tergites, except segment $\mathrm{X}$, brown, legs yellowish; abdominal segment $X$ and segment I of urogomphi yellowish, segment II of urogomphi darker.

Head: as long as wide, widened (Figs 2D, 3A) (in $\mathrm{L}_{3}$ lateral margins more rounded), epicranial part (E) with pair of sword-shaped setae with rough apical part (Ed) (Figs 3A, 14C). Microstructure of central part of nasale as on Fig. 3P. Mandibles (Figs 4F-I, S1F): the ratio length to width 3.5; small tooth on the inner margin (Fig. 4I), (in $\mathrm{L}_{3}$ tooth invisible probably due to jagged inner margins), the apex pointed (Fig. 4G). Antennae (Figs 5A, C, S2A): length ratio of segments I-IV= 1:7.1:9.7:2.7, respectively; ratio length to width of segment II, III, IV: $2.8,4.1,2.5$, respectively; all antennal segments shorter and wider than respective segments in $\mathrm{L}_{3}$; sensory appendage $(\mathrm{Sa})$ tear-shaped with lateral margins arched basally (Fig. 5C). Maxillae (Fig. 6A): cardo 1.2 times as wide as long; stipes 2.6 times as long as wide, dorsal 


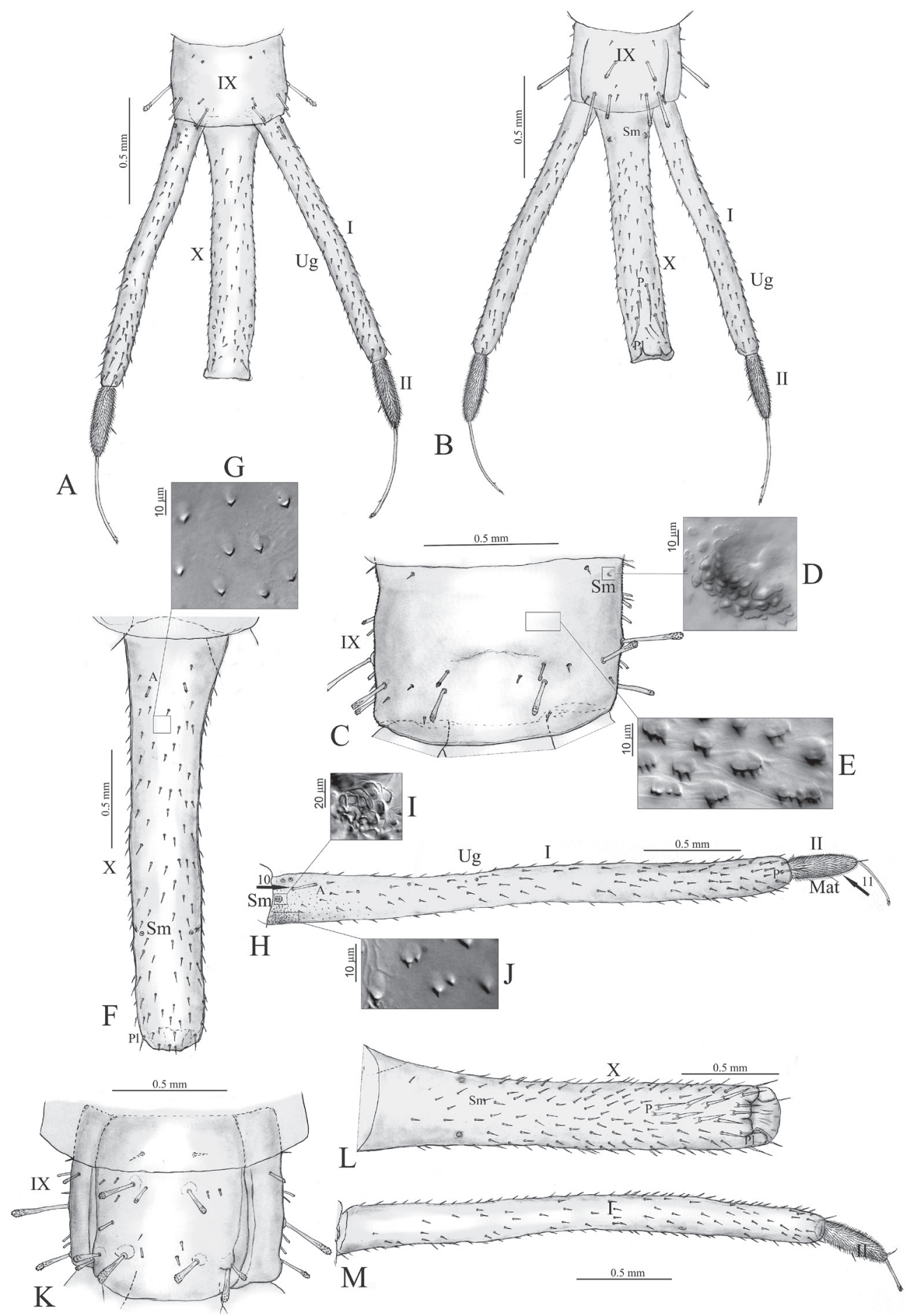

Fig. 10. Astrapaeus ulmi, $1^{\text {st }}$ larval instar (A, B), mature larva (C-M). A, B, abdominal segment IX, X and urogomphi, dorsal (A), ventral (B); C-E, abdominal segment IX, dorsal, with sensilla (D) and microstructure (E); F, G, abdominal segment X, dorsal, with microstructure (G); H-J, right urogomphus, dorsal, with sensilla (I) and microstructure (J); K, abdominal segment IX, ventral; L, abdominal segment $\mathrm{X}$, ventral; M, right urogomphus, ventral. Abbreviations: I, II, segments of urogomphus; IX, X, abdominal segments; A, anterior seta; Mat, macrotrichia; P, posterior seta; Pl, posterolateral seta; Sm, sensilla; Ug, urogomphus. 

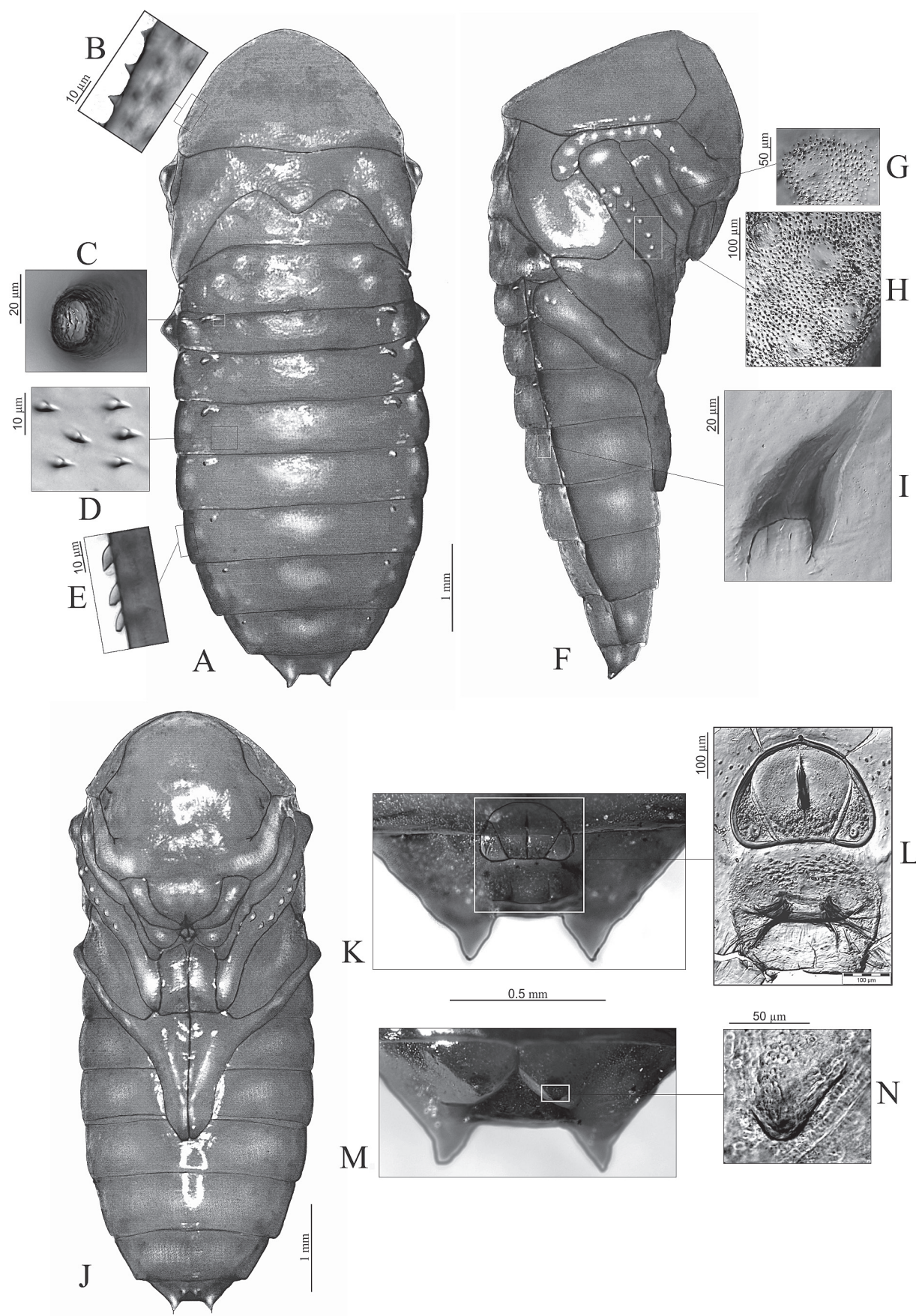

Fig. 11. Astrapaeus ulmi, pupa. A, E, dorsal aspect with microstructure (B, D, E) and spiracle (C); F-I, lateral aspect with protuberances on medium leg $(\mathrm{G}, \mathrm{H})$ and spiracle $(\mathrm{I})$; J, ventral aspect; $\mathrm{K}, \mathrm{L}$, terminal sternite of male with details $(\mathrm{L})$; M, N, terminal sternite of female with details $(\mathrm{N})$.

microtrichia (Dmt) shorter than in $\mathrm{L}_{3}$ and almost absent on cardo. Maxillary palp: segment I almost as long as wide, segment II twice as long as wide with 6 setae, segment III 3.3 times as long as wide. Maxillary seg- ments wider and longer than respective segments in $\mathrm{L}_{3}$. Mala with 2 apical solenidia. Thorax (Figs 7A, C, S3A): pro- meso- and metanotum without some micro setae present in $\mathrm{L}_{3}$. Legs without bifurcate setae on tibia. 


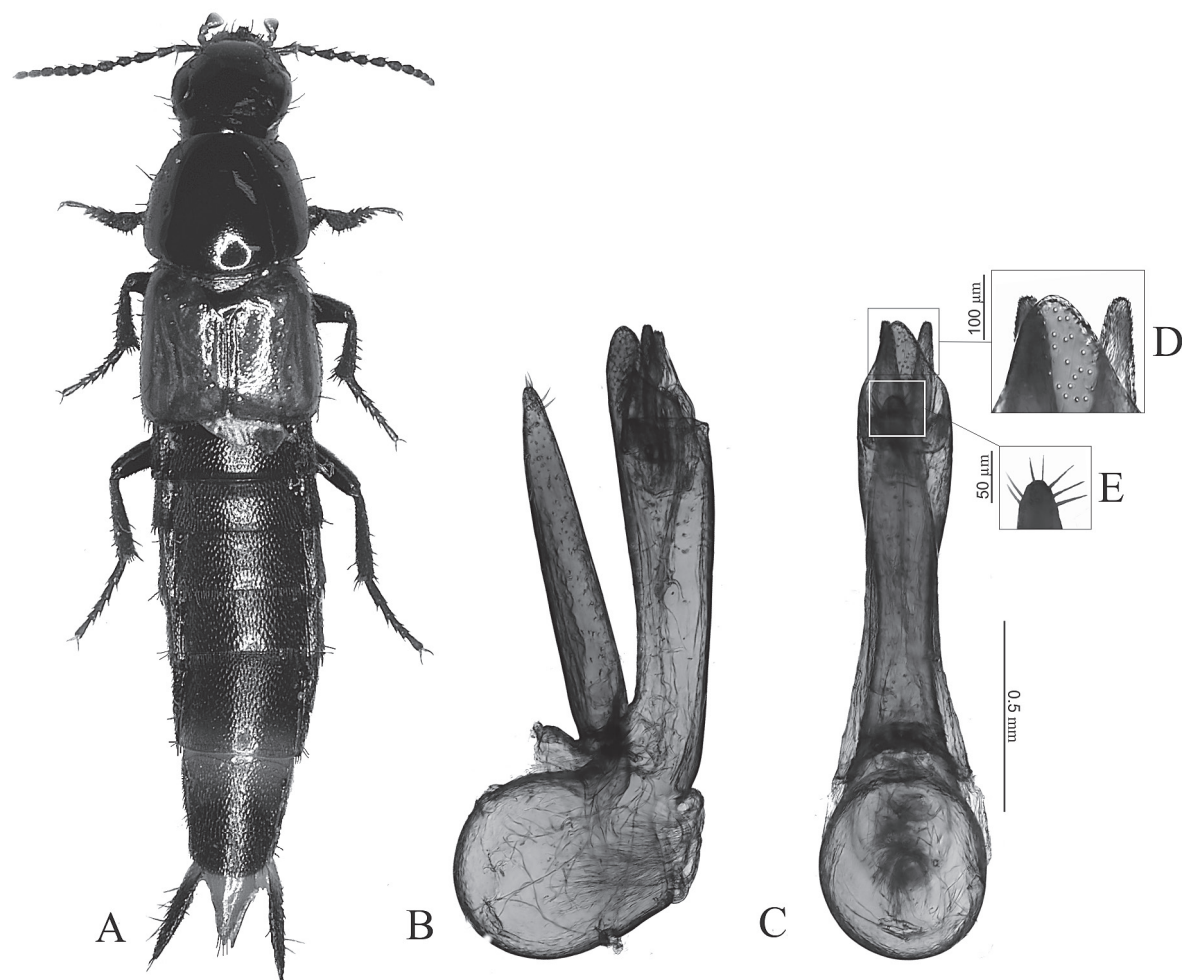

Fig. 12. Astrapaeus ulmi, adult. A. Habitus. B-E, aedeagus, lateral (B), ventral (C) with details of apex (D, E).

Abdomen (Figs 9A, D, 10A-B, S4E): segments I-VIII without numerous short setae present in $\mathrm{L}_{3}$. Segment $\mathrm{X}$ (Figs 10A-B, S4E) without two dorsal club-shaped setae present in $\mathrm{L}_{3}$. Length to width ratio of segments I and II of urogomphus = 10.1 and 3.9, respectively; segment II more slender than such in $\mathrm{L}_{3}$. Ratio length of segment $\mathrm{X}$ : urogomphus segment I : II : apical seta $=$ 7.3: 9.3:1.2:1, respectively. Segment I of urogomphus $3.7 \times$ longer than segment II, apical seta $1.3 \times$ longer than segment II, apex of terminal seta as on Fig. 14D.

\section{Generic diagnosis of Astrapaeus based on pupae}

The combination of characters distinguishing the pupae of Astrapaeus from all genera within the tribe Staphylinini with known pupae (review in Pietrykowska-Tudruj and Staniec, 2010, 2011,2012) includes: 1) body moderately stocky, mean length and width $7.82 \mathrm{~mm}$ and 3.20 $\mathrm{mm}$, respectively; 2) antennae not reaching half of elytral length; 3 ) wings reaching posterior margin of abdominal segment III (first visible); 4) middle tibiae with at least 10 outlines of protuberances; 5) tarsi of hind legs almost reaching half of length of abdominal segment VI (fourth visible).
Pupa (habitus as in Figs 11A-N)

In addition to characters listed in the diagnosis, the pupa possesses the following features: Body length: 7.50-7.98 mm (7.82); body width: 3.03-3.34 mm (3.20); head width: 2.03-2.29 mm (2.17); head length: $2.11-2.26 \mathrm{~mm}$ (2.23); pronotum width: $2.60-2.79 \mathrm{~mm}(2.71)$, pronotum length: $2.36-2.57 \mathrm{~mm}$ (2.48); body brown-orange. Head nearly as long as wide; labrum about 1.7 times as broad as long. Abdominal tergite I 1.7 times as long as tergite II. Tergites: I-IV with functional, V-VIII with atrophied spiracles (Figs 11C, F, I). Terminal sternite: female with double, male with single gonotheca (Figs $11 \mathrm{~K}-\mathrm{N}$ ), both sexes with a pair of very short, terminal prolongations, usually broken.

Life history of Astrapaeus ulmi under laboratory conditions

Oviposition began 16 days after the adults were found in the field (April 16), and lasted until May 9 (23 days in total) (Fig. 15). Eggs were laid separately and dispersed in the substrate of rearing containers. Each of three females laid one, sporadically two eggs per day. 

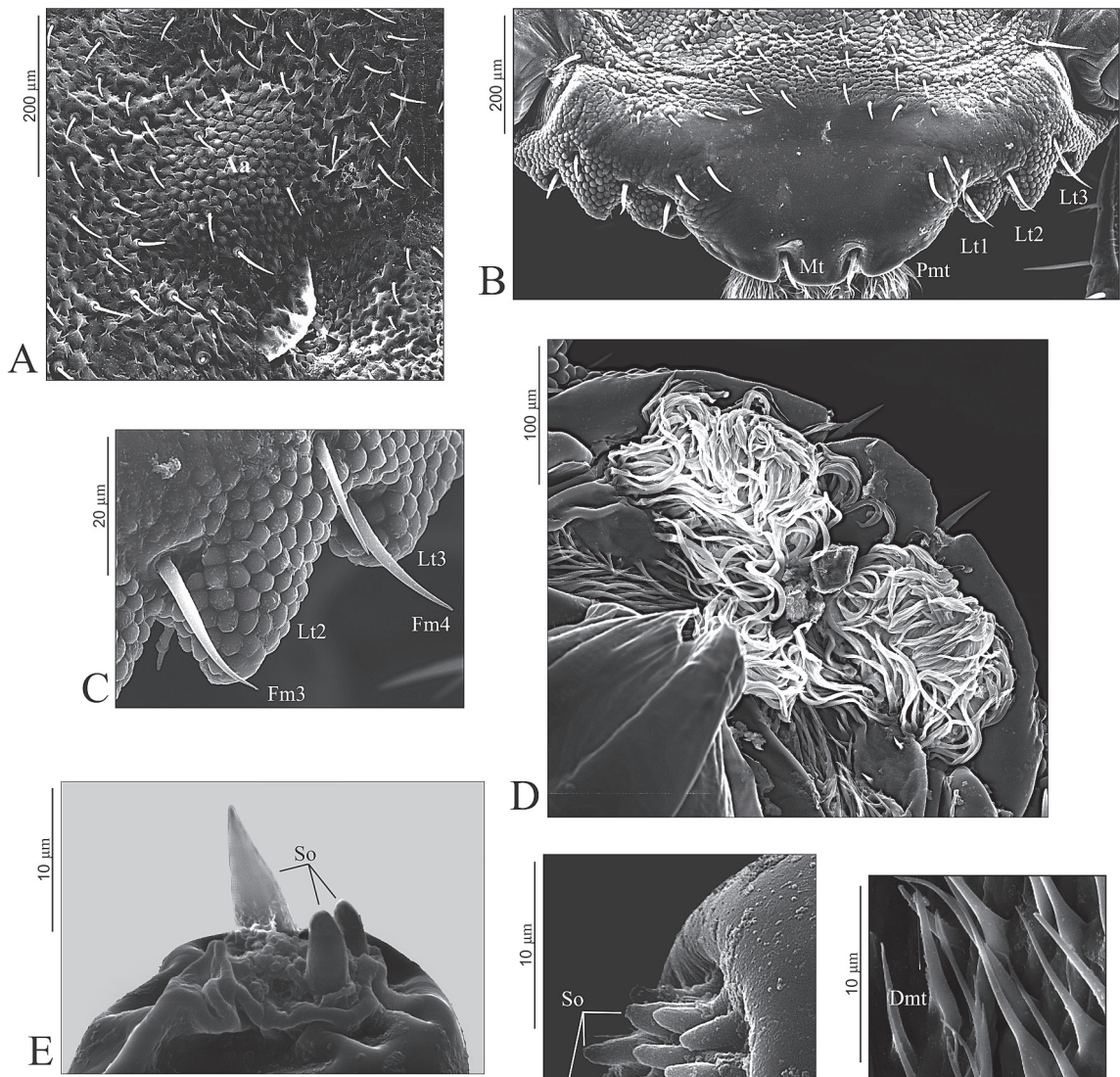

$\mathrm{D}$
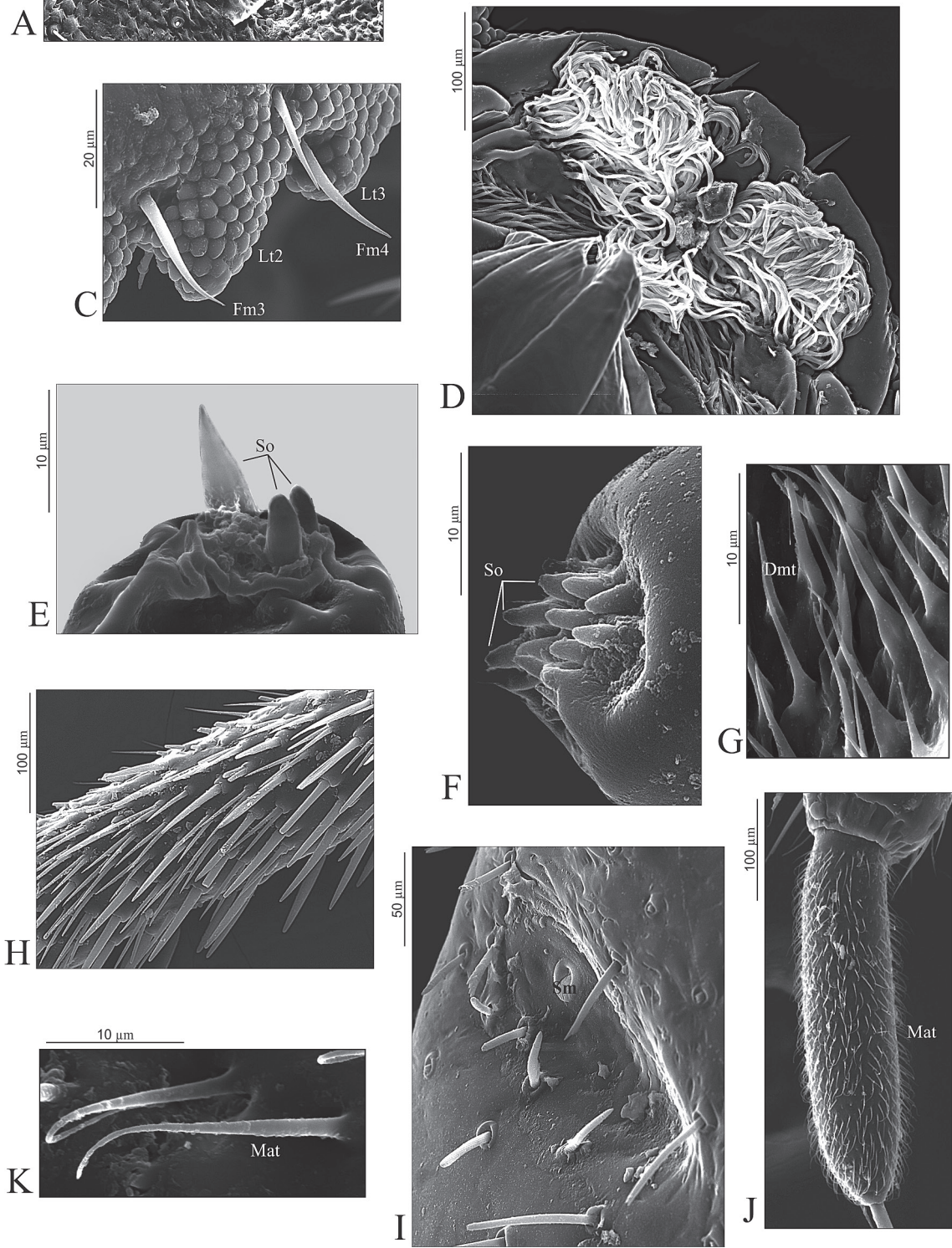

Fig. 13. Astrapaeus ulmi, mature larva. A, part of epicranium with anterior area; B, anterior part of nasale; C, lateral teeth of nasale; D, epipharynx; E, apex of mala; F, apex of labial palp; G, microtrichia on stipes, dorsal; H, setae on fore leg, anterior; I, lateral side of pronotum; J, segment II of urogomphi; K, macrotrichia on segment II of urogomphi. Abbreviations: Aa, anterior area; Dmt, dorsal microtrichia; Fm, frontal marginal seta; Lt, lateral tooth; Mat, macrotrichia; Mt, median tooth; Pmt, paramedian tooth; Sm, sensilum; So, solenidium. 

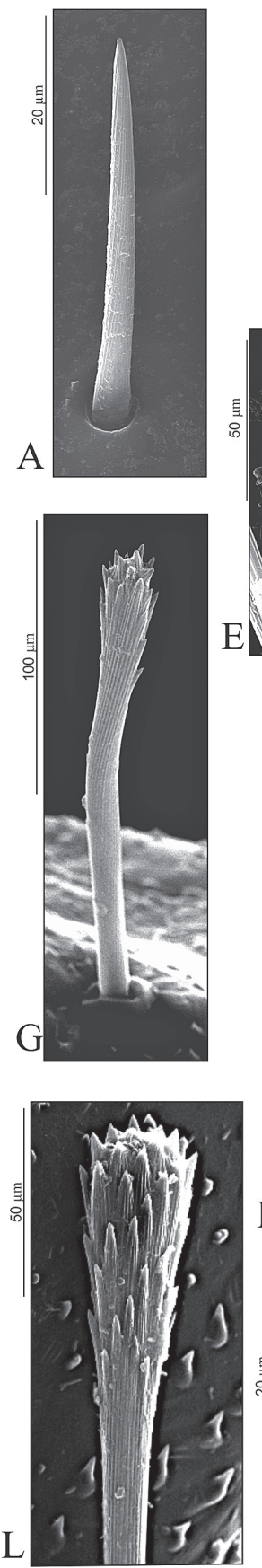

M
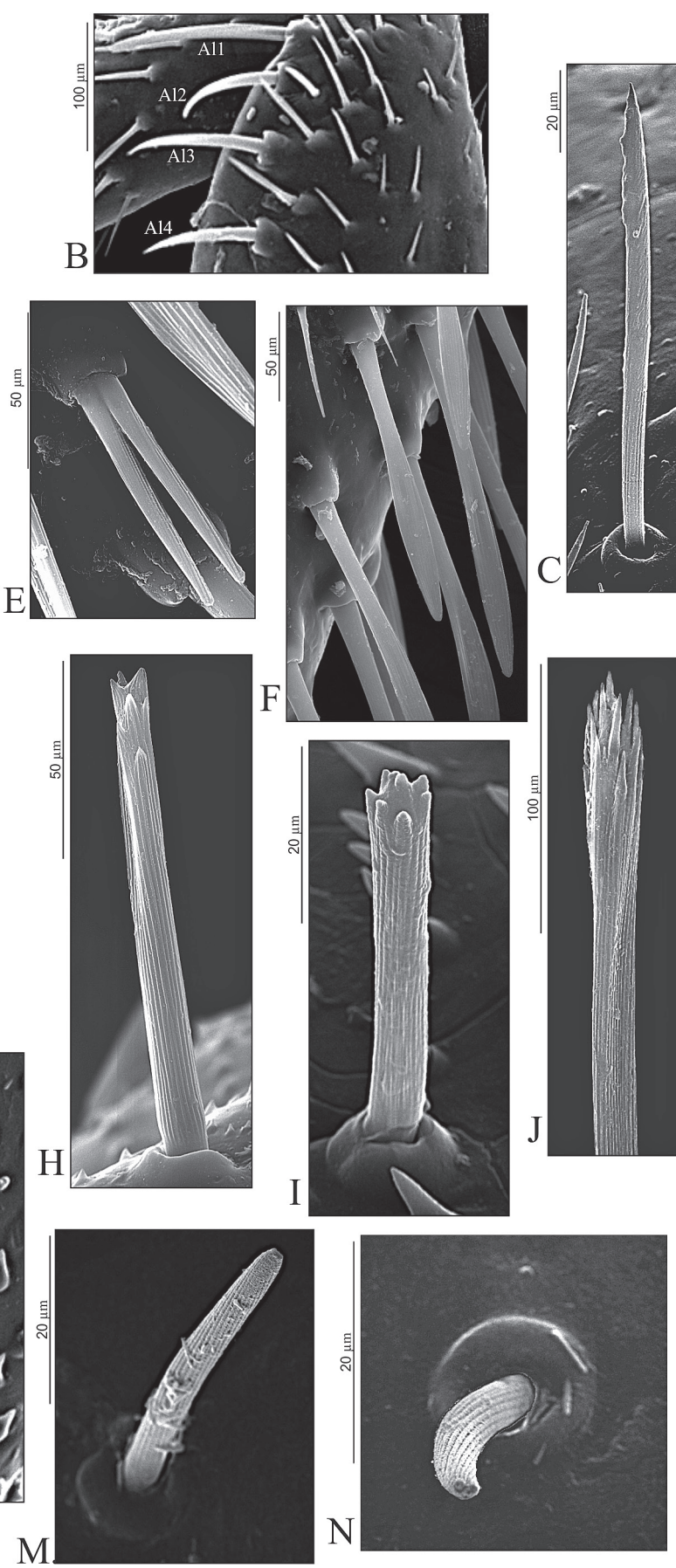
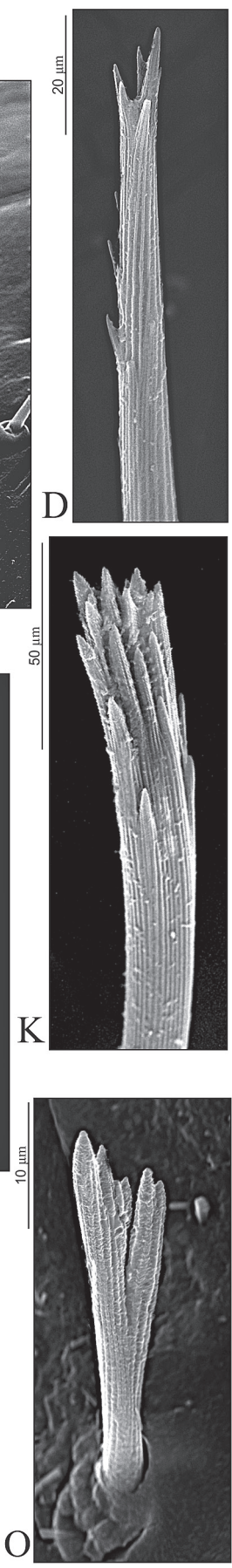

Fig. 14. Astrapaeus ulmi, types of setae, $1^{\text {st }}$ larval instar (C, D), mature larva (A-B, E-O). A, simple seta on dorsal side of head; B, long spine-shaped setae on fore femur, anterior; C, sword-shaped seta on dorsal side of head; D, anterior part of apical seta on segment II of urogomphus; E, bifurcate seta on fore tibia, anterior; F, spear-shaped setae on fore tibia, posteroventral; $\mathrm{G}, \mathrm{H}$, club-shaped seta on fore coxa $(\mathrm{G})$ and medium coxa $(\mathrm{H})$, anterior; I, short, club-shaped seta on abdominal segment III; J, anterior part of apical seta on segment II of urogomphus; K, apex of seta on dorsal side of head, mature larva; L, long, club-shaped seta on abdominal segment III, dorsal; M, $\mathrm{N}$, stick-shaped setae on pronotum; $\mathrm{O}$, fun-shaped seta on pronotum. Abbreviations: Al, anterolateral seta. 


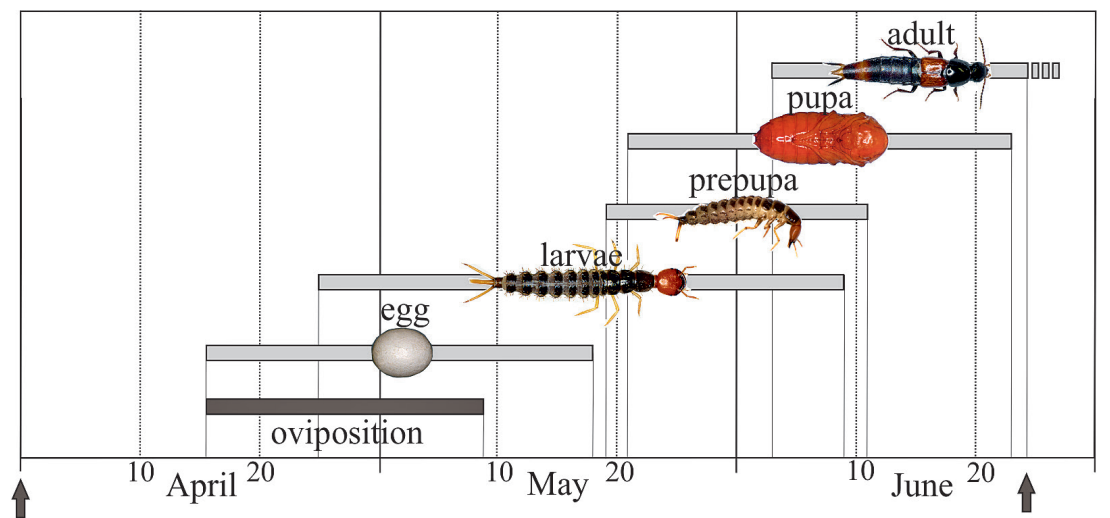

begining of breeding the end of breeding
Fig. 15. Occurence of various developmental stages of Astrapaeus ulmi rearing in the laboratory.
Throughout the time of oviposition, the females laid 69 eggs in total. After oviposition females remained alive for an additional two weeks until they were killed and preserved. The period of embryonic development varied from 8 to 12 days (mean 10 days). Larval specimens occurred in laboratory from April 25 to June 9, 46 days in total (Fig. 15). Developmental time of larval stages (t. $22 \pm 2^{\circ} \mathrm{C}$ ) ranged as follows: 5-9 (mean 6.9) days for the first instar 5-8 (mean 6.3) days for the second instar; and 6-9 (mean 7.8) days for the third instar. Pupae appeared from May 21 to June 24 during a period of 35 days. Mean duration of pupal development was 12.7 days. During the 16-day period before oviposition, adult beetles were fed live ant larvae, an easy to find food source that was successfully used in our numerous rearing experiments for other genera of Staphylinini. Contrary to the adults, all larval instars of A. ulmi readily fed on live springtails and immature Porcelio isopods (see below). Two or one days before pupation, larvae became less active, stopped feeding, and stayed immobile in the soil on the bottom of the rearing chambers with their head and tip of abdomen folded downward. Like most other Staphylinini, larvae of A. ulmi made a pupal chamber by compacting soil around the body. Adults of the new generation appeared from June 3 . The postembryonic development of $A$. ulmi individuals from a hatched first instar larva to emergence of adults lasted for 35.7 days, on average (Fig. 15).

\section{Observed diet preference of Astrapaeus ulmi}

Nothing is known about the feeding specialization of adult or larval stages of $A$. ulmi under natural conditions. It is presumed that they are predators and feed on in- vertebrates of relevant size, similar to other species from the tribe Staphylinini for which there are observations in natural conditions (e.g., Frank, 1967; Hunter et al., 1989; Majka et al., 2006; Chatzimanolis, 2003; Frank and Morón, 2012). Generally, feeding details of the predaceous rove beetles are very poorly known (review in Thayer, 2005), with most observations performed under laboratory conditions rather than in nature. In the laboratory, various adults and larvae of Staphylinini were successfully fed with a variety of food sources like eggs and larvae of flies, caterpillars and pupae of butterflies, adult and larval beetles, aphids, freshly killed mealworms, amphipods and enchytraeid worms, snails, without any distinct preference for prey of a certain taxonomic group (e.g., Orth et al., 1976; Topp and Ring, 1988; Good and Giller, 1991; Schmidt, 1994a, b). In our previous laboratory observations on a diversity of larval Staphylinini (e.g., Staniec and PietrykowskaTudruj, 2007; Pietrykowska-Tudruj and Staniec, 2012), larvae accepted springtails, larvae of various undetermined species of ants, and domestic crickets.

In the present study, larvae of A. ulmi were initially given a food choice consisting of springtails and ant larvae of various body sizes. Astrapaeus ulmi larvae readily ate only live springtails, and ignored either dead springtails, or live or freshly killed ant larvae. However, a diet restricted to springtails significantly hindered the rate of larval development, especially during the second and third instar. For example, development of the second instar lasted 11 days compared to the average 6 days of other specimens with a different diet (see below). The former larvae moulted at most twice, and died at the beginning of their last (third) instar. Neither of them reached the pupal stage. 


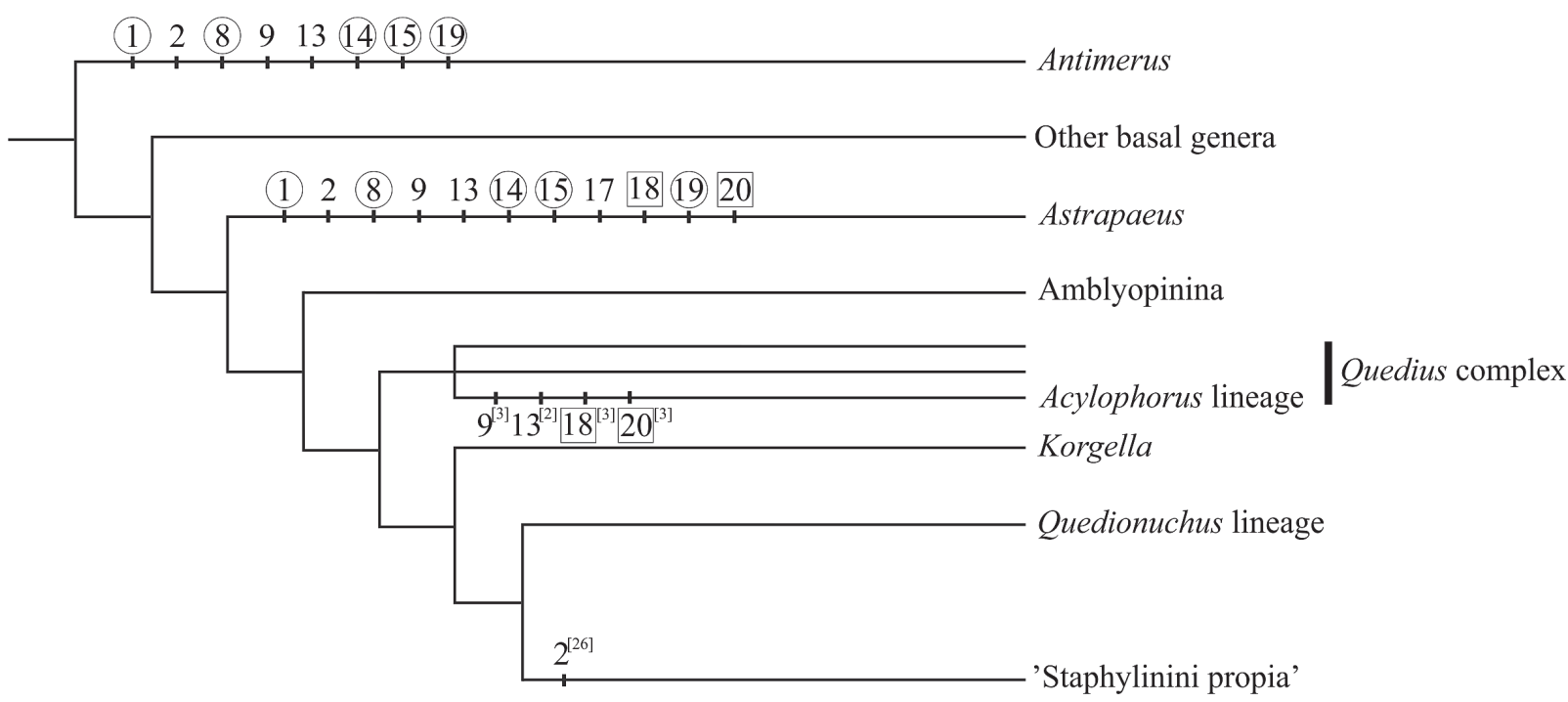

Fig. 16. Distribution of some larval characters of Astrapaeus on the hypothetical phylogeny of Staphylinini (phylogenetic tree simplified from Brunke and Solodovnikov 2013). Numbers mapped on the branches (1, 2, 8, 9, 13-15, 17-20) indicate respective characters from Table 1 shared by Astrapaeus with no more than other two lineages of Staphylinini; of them numbers in circle indicate characters shared by Astrapaeus and Antimerus only, numbers in squares indicate characters shared by Astrapaeus and Acylophorus-lineage only. Smallersize numbers in square brackets after character indicate respective taxa from Table 1: [2] - Acylophorus wagenschieberi, [3] - Anaquedius vernix, [26] - Platydracus latebricola.

When we noted the slow development of A. ulmi larvae fed springtails, immature Porcelio isopods were offered to the first and second instar larvae. Beetle larvae of both instars readily attack live (untouched) or damaged (with cut integument) isopods. Porcelio isopods were chosen as a food item because they were common in the habitat where our specimens of A.ulmi came from, and they were hypothesised as a natural food source. Adding isopods resulted in a shorter duration of the second instar (6 days on average), and a lower mortality rate, compared to that observed among larvae with a non-Porcelio diet. Several of the Porcelio fed larvae pupated, and some of them reached the adult stage.

Terrestrial isopods have seldom been reported as food for adults or larvae of various Staphylinini (Wheater, 1987; Good and Giller, 1991; Whitehead, 1999; Chatzimanolis, 2003, 2004) and accounts exist for several species of Ocypus, for Quedius molochinus, and, doubtfully, for Physetops (Solodovnikov and Grebennikov, 2005). We assume that isopods are natural prey of $A$. ulmi larvae that determine their growth and development, at least for individuals of our source population, which is isolated at the northernmost distributional limit. Since the composition and relative abundance of available prey species vary across the distribution range of $A$. ulmi, its diet may vary accordingly. Observations of this species under natural conditions, including morphological or genetic examination of the gut contents of adults and larvae may shed light on the abovementioned questions.

According to Tauber and Tauber (1987), females of some insects need natural prey, that provide the necessary stimulus for oviposition. Whether and how the isopod-based diet affects reproductive behaviour in $A$. ulmi females is unknown. Females of A. ulmi fed with ant larvae under laboratory conditions developed and laid fertile eggs. Therefore, immature ants seem to be a sufficient food source to commence oviposition and provided nutrients for egg development. On the other hand, females that were collected for our rearing experiments were previously exposed to natural prey and thus may have obtained the necessary stimuli before they were transferred to the laboratory.

Possible phylogenetic signal of the immature stages of Astrapaeus for the tribe Staphylinini

A detailed comparison of the larvae of Astrapaeus with other larvae of the tribe Staphylinini is summarized in 
Table 1. Larval characters that are unique to Astrapaeus are provided in Table 2. Within Staphylinini, the larva of A. ulmi shares the highest number of characters with that of the recently revised (Solodovnikov and Newton, 2010) Australian genus Antimerus. The Astrapaeus larva also shares several characters with various members of Quediina (in the more restricted, phylogenetically informed sense of Chatzimanolis et al., (2010)), the subtribe where it was traditionally placed. However, markedly fewer characters are shared with members of Quediina compared to those shared between Astrapaeus and Antimerus. Furthermore, numerous non-chaetotaxic and many more chaetotaxic characters strongly differentiate the larva of A. ulmi from members of Quediina (Tables 1-2). It is noteworthy that the urogomphi are longer than the pygopod in larval A. ulmi, while they are distinctly shorter than the pygopod in all known Quediina; the latter is a stable diagnostic feature of the subtribe Quediina, at least among the north temperate fauna (Paulian, 1941; Pototskaya, 1967; Kasule, 1970; LeSage, 1984). The larva of Astrapaeus shares even fewer characters with other subtribes of Staphylinini (Table 1), in agreement with evidence derived from adult morphology.

Although it can be concluded that larval morphology of Astrapaeus does not support the traditional placement of this genus in Quediina, it is impossible to extract true phylogenetic information from larval characters without a phylogenetic analysis. Since the available larval data for Staphylinini are still too fragmentary for a robust analysis (Pietrykowska-Tudruj et al., 2012), we refrain from this here. However, if we optimize the newly discovered, non-unique larval characters of Astrapaeus from Table 1 on a schematic representation of the Staphylinini phylogeny as it is currently known from adult morphology (Brunke and Solodovnikov, 2013), some insight on their potential phylogenetic value may be gained (Fig. 16).

Approximately half of the characters from Table 1 shared by several and always phylogenetically remote lineages were not mapped in Fig. 16 as they were assumed to be homoplasious. Of the characters shared by no more than three major lineages of Staphylinini (characters 1, 2, 8, 9, 13-15, 17-20 in Table 1, all mapped in Fig. 16), the majority is shared only between Astrapaeus and Antimerus (characters 1, 8, 14, 15, 19). Based on adult morphology, the phylogenetic position of Antimerus remains hitherto unclear (Solodovnikov and Newton, 2010; Brunke and Solodovnikov, 2013). Larval characters seem to enforce a previous hypothesis that Antimerus and Astrapaeus may be placed rather close to each other in a phylogeny (Brunke and Solo- dovnikov, 2013). Which of the characters shared by Antimerus and Astrapaeus larvae are symplesiomorphies, synapomorphies or homoplasies, remains be established. However, assuming that the currently known major phylogenetic pattern for Staphylinini is correct, the presence of some of those shared characters can be predicted for the larvae of other basal lineages of Staphylinini (e.g., Valdiviodes and Afroquedius).

Discovery and description of the larvae of these other isolated lineages is highly desirable. Also noteworthy are characters 9 and 13, shared by Astrapaeus, Antimerus and some genera of Quediina from the 'Acylophorus-lineage', as well as characters 18 and 20 shared only by Astrapaeus and the 'Acylophorus-lineage'. According to Brunke and Solodovnikov (2013), the 'Acylophorus-lineage' is a member of the speciesrich and largely unresolved 'Quedius-complex'. Distribution of characters $9,13,18$ and 20 on the tree branches that are not sister but separated only by few nodes (Fig. 16) suggests that they are likely symplesiomophies. If so, their presence in the larvae of the 'Acylophorus-lineage' suggests a basal position of that lineage within the 'Quedius-complex'. This was unclear from adult morphology (Solodovnikov and Brunke, 2013), but evident from molecular data (Chatzimanolis et al., 2010). Finally, character 2, shared by Astrapaeus, Antimerus and Platydracus latebricola from the 'Staphylinini propria' (a clade uniting the subtribes Staphylinina, Philonthina, Anisolinina and Xanthopygina), seems to have a parallel development, at least in Platydracus.

Given the adult morphology-based sister relationships of Astrapaeus with Parisanopus and 'Quedius' subgenus Cyrtoquedius (Brunke and Solodovnikov, 2013), the discovery of their larvae in Central and South America would be highly interesting. If the above hypothesis of Brunke and Solodovnikov (2013) is correct, larvae of Parisanopus and Cyrtoquedius should have at least some characters highlighted in Fig. 16, and perhaps some of the characters hitherto unique to Astrapaeus (Table 2).

The pupae of Staphylinini are known for a much smaller number of taxa than larvae and have much simpler morphology. Therefore, their phylogenetic evaluation is premature and not attempted here.

\section{Discussion and conclusions}

As outlined in the introduction, immature stages may provide potential signal for a thorough phylogenetic 
study of the tribe Staphylinini. Unfortunately, the immatures of many taxa of key phylogenetic interest are unknown due to difficulties in their collection and identification. The rearing-based discovery of the immature stages of A. ulmi is very exciting in this context, since this species has been hypothesized to represent a lineage of the utmost phylogenetic interest.

Even the present, preliminary comparison of the newly discovered immature stages, especially larvae, across the tribe Staphylinini quickly revealed the isolated position of A. ulmi within the tribe, and outside the subtribe Quediina. This alone is valuable because the adults of A. ulmi overall resemble those of Quediina, such that it was only after a series of thorough phylogenetic analyses before its placement was doubted. Although our growing, though incomplete dataset on immature Staphylinini did not provide evidence for a sister taxon to Astrapaeus, it generated new phylogenetically significant insights. Noteworthy are the significant amount of characters shared between the larvae of Astrapaeus and Antimerus, and, to a lesser extent, between those and the genera of the 'Acylophoruslineage', taxa previously hypothesized to be related in morphological and molecular analyses. Inclusion of morphological data from immatures in a total evidence analysis combining adults, larvae and molecular data seems very promising for investigating sister relationships of those lineages.

\section{Acknowledgements}

The first author acknowledges the Synthesys grant from the European Commission for funding a visit to the Natural History Museum of Denmark. We are very thankful to M. Fikáček (Prague), and one anonymous reviewer, for critical comments and suggestions leading to an improved version of this paper. Finally, A. Brunke (Copenhagen, originally from Canada) is acknowledged for improving the English language of the manuscript.

\section{References}

Ashe JS, Watrous LE. 1984. Larval chaetotaxy of Aleocharinae (Staphylinidae) based on a description of Atheta coriaria Kraatz. Coleopterists' Bulletin 38: 165-179.

Assing V, Schülke M. 2012. Freude-Harde-Lohse-Klausnitzer Die Kafer Mitteleuropas. Band 4. Staphylinidae I. Zweite neubearbeitete Auflage. Spektrum Akademischer Verlag, Heidelberg.

Brunke A, Solodovnikov A. 2013. Alesiella gen. nov., and a newly discovered relict lineage of Staphylinini (Coleoptera: Staphylinidae). Systematic Entomology 38: 689-707.
Chatzimanolis S. 2003. Natural history and behaviour of Nordus fungicola (Coleoptera: Staphylinidae). Annals of the Entomological Society of America 96: 225-230.

Chatzimanolis S. 2004. A revision of the neotropical genus Nordus (Coleoptera: Staphylinidae). Entomologische Abhandlungen 62: 3-64.

Chatzimanolis S, Cohen I, Schomann A, Solodovnikov A. 2010. Molecular phylogeny of the mega-diverse rove beetle tribe Staphylinini (Insecta, Coleoptera, Staphylinidae). Zoologica Scripta 39: 436-449.

Dajoz R, Caussanel C. 1968. Morphologie et biologie d'un Coléoptères prédateur Creophilus maxillosus (Staphylinidae). Cahiers des Naturalistes, Bulletin des Naturalistes Parisiens 24: 65-102.

Frank JH. 1967. The insect predators of the pupal stage of the winter moth, Operophtera brumata (L.) (Lepidoptera: Hydriomenidae). The Journal of Animal Ecology 36: 375-389.

Frank JH, Morón MA. 2012. Natural history of four species of Platydracus Thomson (Coleoptera: Staphylinidae) in Heliconia bourgaeana Petersen (Zingiberales: Heliconiaceae) flower bracts. Insecta Mundi 258: 1-12.

Fülöp D. 2005. Rove beetles (Coleoptera: Staphylinidae) of the Tisza Valley. Pp. 97-147 in: Gallé L, ed, Vegetation and Fauna of Tisza River Basin I. TISCIA Monograph Series, 7.

Good JA, Giller PS. 1991. The diet of predatory staphylinid beetles - a review of records. Entomologist's Monthly Magazine 127: 77-89.

Gravenhorst JLC. 1802. Coleoptera Microptera Brunsvicensia nec non Exoticorum quotquot exstant in collectionibus Entomologorum Brunsvicensium in genera familias at species distribuit. Brunsvigae I-LXVI + 1-207.

Gusarov VI, Koval AG. 2002. A revision of the genus Heinzia Korge, 1971 (Coleoptera: Staphylinidae: Quediina), with description of a new species and its probable larva. Zootaxa 69: 1-19.

Hance D. 2007. Astrapaeus ulmi (Rossi, 1790) (Staphylinidae) in Britain. The Coleopterist 16: 1-2.

Herman L. 2001. Catalog of the Staphylinidae (Insecta, Coleoptera): 1758 to the end of the second millennium. Bulletin of the American Museum of Natural History 265: 4218 pp.

Horion A. 1965. Faunistik der mitteleuropaischen Kafer. Vol. 10: Staphylinidae, 2. Teil, Paederinae bis Staphylininae. Uberlingen-Bodensee, $\mathrm{xv}+335 \mathrm{pp}$.

Hunter JS, Bay DE, Fincher GT. 1989. Laboratory and field observations on the life history and habits of Philonthus cruentatus and Philonthus flavolimbatus. Southwestern Entomologist 14: 41-47.

Kasule FK. 1970. The larvae of Paederinae and Staphylinidae (Coleoptera: Staphylinidae) with keys to the known British genera. Transactions of the Royal Entomological Society of London 122: 49-80.

Kreissl E. 1987. Astrapaeus ulmi (Rossi) - neu für die Steiermark (Hex., Coleoptera, Staphylinidae). Mitteilungen der Abteilung für Zoologie am Landesmuseum Joanneum 40: 65-66.

LeSage L. 1984. The larva of Anaquedius vernix (Coleoptera: Staphylinidae). Canadian Entomologist 116: 189-196.

Majka CG, Klimaszewski J, Lauff RF. 2006. New Coleoptera records from owl nests in Nova Scotia, Canada. Zootaxa 1194: 33-47. 
Orth RE, Moore I, Fisher TW, Legner EF. 1976. Biological notes on Ocypus olens, a predator of Brown Garden Snail, with descriptions of the larva and pupa (Coleoptera: Staphylinidae). Psyche 82: 292-298.

Paulian R. 1941. Les premiers états des Staphylinoidea (Coleoptera).Étude de morphologie comparée. Mémoires du Muséum National d'Histoire Naturelle 15: 1-361.

Pietrykowska-Tudruj E, Staniec B.2010. The pupae of Philonthus politus (Linné, 1758), Gabrius astutus (Erichson, 1840) and Quedius cinctus (Paykull, 1790) (Coleoptera: Staphylinidae: Staphylininae). Genus 21: 31-42.

Pietrykowska-Tudruj E, Staniec B. 2011. The morphology of the pupae of six species of Philonthina (Coleoptera: Staphylinidae: Staphylinini) with taxonomic remarks. Zootaxa 2865: 53-67.

Pietrykowska-Tudruj E, Staniec B. 2012. Comparative larval morphology of Platydracus and Staphylinus (Staphylinidae: Staphylinini: Staphylinina) with notes on their biology and redescription of the pupa of Staphylinus. Zootaxa 3580: 24-42.

Pietrykowska-Tudruj E, Staniec B, Solodovnikov A. 2012. Discovery of the Quedius antipodum Sharp larva from New Zealand: phylogenetic test of larval morphology for Staphylinini at the intratribal level (Coleoptera: Staphylinidae). Systematic Entomology 37: 360-378.

Pototskaya VA. 1967. Opredelitel' lichinok korotkonadkrylykh zhukov evropeiskoi chasti SSSR. Academiya Nauk SSSR, Izdatel'stvo Nauka, Moskva, pp 120.

Schmidt DA. 1994a. Notes on the biology and a description of the egg, third instar larva and pupa of Platydracus tomentosus (Gravenhorst) (Coleoptera: Staphylinidae). Coleopterists Bulletin 48: 3-318.

Schmidt DA. 1994b. Notes on the biology and a description of the egg, third instar larva and pupa of Neobisnius sobrinus (Coleoptera: Staphylinidae). Transactions of the Nebraska Academy of Sciences 21: 55-61.

Schmidt DA. 1996. Description of the immatures of Erichsonius alumnus Frank and E. pusio (Horn) (Coleoptera: Staphylinidae). Coleopterists Bulletin 50: 205-215.

Smetana A. 1958. Drabčíkovití - Staphylinidae: 1. Staphylininae (řád: brouci - Coleoptera). Fauna ČSR 12: 1-437.

Solodovnikov A. 2005. Natalignathus, gen. nov. and larvae of Atanygnathus: a missing phylogenetic link between subtribes Quediina and Tanygnathinina (Coleoptera: Staphylinidae: Staphylininae: Staphylinini). Invertebrate Systematics 19: 75-98.

Solodovnikov AYu. 2006. Adult and larval descriptions of a new termitophilous genus of the tribe Staphylinini with two species from South America (Coleoptera: Staphylinidae). Proceedings of the Russian Entomological Society 77: 274-283.

Solodovnikov A. 2007. Larval chaetotaxy of Coleoptera (Insecta) as a tool for evolutionary research and systematics: less confusion, more clarity. Journal of Zoological Systematics and Evolutionary Research 45: 120-127.

Solodovnikov A. 2012. Rove beetle subtribes Quediina, Amblyopinina and Tanygnathinina: systematic changes affecting Central European fauna (Coleoptera, Staphylinidae, Staphylinini). Zookeys 162: 25-42.

Solodovnikov AYu, Grebennikov KA. 2005. Revision of Physetops Mannerheim, 1830, a monotypic genus with the polymorphic species P. tataricus (Pallas, 1773) (Coleoptera: Staphylinidae: Staphylininae). Mitteilungen aus dem Museum fur Naturkunde in Berlin - Zoologische Reihe 81: 67-80.
Solodovnikov A, Newton AF. 2010. Revision of the rove beetle genus Antimerus (Coleoptera, Staphylinidae, Staphylininae), a puzzling endemic Australian lineage of the tribe Staphylinini. ZooKeys 10: 21-63.

Solodovnikov A, Schomann A. 2009. Revised systematics and biogeography of 'Quediina' of Subsaharan Africa: new phylogenetic insights into the rove beetle tribe Staphylinini (Coleoptera: Staphylinidae). Systematic Entomology 34: 443446.

Solodovnikov A, Tarasov S, Ren D. 2013. Extinct and extant rove beetles meet in the matrix: Early Cretaceous fossils shed light on the evolution of a hyperdiverse insect lineage (Coleoptera: Staphylinidae: Staphylininae). Cladistics 360403.

Stan M. 2005. Rove beetles (Coleoptera: Staphylinidae) from the Danube floodplain area, Giurgiu Sector (Romania). Travaux du Muséum National d'Histoire Naturelle, Grigore Antipa' 48: 87-101.

Staniec B. 2003. Morphology of the mature larva and pupa of Quedius brevicornis (Thomson, 1860) (Coleoptera: Staphylinidae). Annales Zoologici 53: 673-680.

Staniec B. 2004. Description of the developmental stages of Hesperus rufipennis (Gravenhorst, 1802) (Coleoptera, Staphylinidae), with comments on its biology. Annales Zoologici 54: 287-500.

Staniec B. 2005a. A description of the developmental stages of Acylophorus wagenschieberi Kiesenwetter, 1850 (Coleoptera, Staphylinidae), with notes on the biology and eggs parasite. Deutsche Entomologische Zeitschrift 52: 97-113.

Staniec B. 2005b. Description of the developmental stages of Atanygnathus terminalis (Erichson, 1839) (Coleoptera, Staphylinidae), with comments on its biology. Deutsche Entomologische Zeitschrift 52: 173-190.

Staniec B, Pietrykowska-Tudruj E. 2007. Developmental stages of Philonthus rubripennis Stephens, 1832 (Coleoptera, Staphylinidae, Staphylininae) with comments on its biology. Deutsche Entomologische Zeitschrift 54: 95-113.

Staniec B, Pietrykowska-Tudruj E. 2009. Immature stages of Rabigus tenuis (Fabricius, 1792) (Coleoptera, Staphylinidae, Staphylininae) with observations on its biology and taxonomic comments. Belgian Journal of Zoology 139: 22-39.

Staniec B, Pietrykowska-Tudruj E. 2010. The first description of the mature larva of Bisnius nitidulus (Gravenhorst, 1802) (Coleoptera: Staphylinidae). Genus 21: 205-217.

Staniec B, Pilipczuk J, Pietrykowska-Tudruj E. 2009. Morphology of Immature Stages and Notes on Biology of Ocypus fulvipennis Erichson, 1840 (Coleoptera: Staphylinidae). Annales Zoologici 59: 47-66.

Staniec B, Pietrykowska-Tudruj E, Sałapa D. 2011. Description of the egg and larva of Paederidus Mulsant \& Rey, 1878 (Coleoptera, Staphylinidae, Paederinae) based on the two European species. Zootaxa 2888: 39-56.

Tauber CA, Tauber MJ. 1987. Food specificity in predaceous insects: a comparative ecophysiological and genetic study. Evolutionary Ecology 1: 175-186.

Thayer MK. 2005. Chapter 11.7 Staphylinidae Latreille, 1802. Pp. 296-344 in: Beutel R, Leschen R, eds, Handbook of Zoology: A natural history of the phyla of the animal kingdom. De Gruyter, New York, 
Tikhomirova AL. 1973. Morfoekologicheskiye osobennosti i filogenez, Stafilinid (s katalogom fauny SSSR) [Morpho-ecological features and phylogeney of Staphylinids (with a catalogue of the fauna of the USSR)]. Akademiia Nauk SSSR, Moscow, pp. 191 (in Russian).

Topp W, Ring RA. 1988. Adaptations of Coleoptera to the marine environment. I. Observations on rove beetles (Staphylinidae) from sandy beaches. Canadian Journal of Zoology 66: 24642468 .

Wheater CP. 1987. Observations on the food of Staphylinus olens Müller (Col., Staphylinidae). The Entomologist's Monthly Magazine 123: 116.
Whitehead PF. 1999. Observations on Ocypus ater (Gravenhorst, 1802) (Staphylinidae) including breeding inside a house. The Coleopterist 8: 22.

Wojas T. 2011. Potwierdzenie występowania Astrapaeus ulmi (Rossi, 1790) (Coleoptera: Staphylinidae: Staphylininae) w Polsce. Wiadomości Entomologiczne 30: 27-30.

Received: 22 July 2013

Revised and accepted: 6 December 2013

Published online: 10 January 2014

Editor: H. de Jong

\section{Online supplementary information (SI)}

S1. Measurements of the larvae of the first $\left(\mathrm{L}_{1}\right)$ and the third $\left(\mathrm{L}_{3}\right)$ instars of $A$. ulmi $(1=$ length; $\mathrm{w}=$ width; measurements in $\mathrm{mm}$ ).

S2. Astrapaeus ulmi, $1^{\text {st }}$ larval instar (D, F), mature larva (A-C, E, G, H). A, stemmata; B, C, nasale; D, E, tentorial pits; F, G, right mandible, ventral; $\mathrm{H}$, left mandible, dorsal. Abbreviations: L, lateral seta; Lsm, lateral sensillum; T, tooth; Tp, tentorial pit; Ts, transverse suture.

S3. Astrapaeus ulmi, $1^{\text {st }}$ larval instar (A), mature larva (B-G). A, B, right antenna, ventral; C, right antennal segment IV, dorsal; D, E, anterior part of antennal segments third (D) and fourth (E); F, right maxillary palp, palpifer and mala, ventral; $\mathrm{G}$, details of right mala, dorsal. Abbreviations: I-IV, segments; $\mathrm{A}_{1-3}$, setae; Ma, mala; Pf, palpifer; Sa, sensory appendages; So, solenidium.

S4. Astrapaeus ulmi, $1^{\text {st }}$ larval instar (A), mature larva (B-G). A, B, right half of metanotum. C, meso- and metathorax, ventral; D-F, details of fore tarsungulus, anterior with microstructure (E, F); G, coxa, femur, tibia and tarsungulus of medium leg, anterior. Abbreviations: A, anterior seta; Ad, anterodorsal seta; Al, anterolateral seta; Cx, coxa; Fe, femur; L, lateral seta; $\mathrm{P}$, posterior seta; $\mathrm{Pl}$, posterolateral seta; $\mathrm{Sm}$, sensilla; Te, tergite; Tb, tibia; Tu, tarsungulus.

S5. Astrapaeus ulmi, $1^{\text {st }}$ larval instar (E), mature larva (A-D, F-I). A, B, abdominal segment I (A) and II (B); C, D, abdominal segment IX, X and urogomphi, dorsal (C) and ventral (D); E-I, right side of abdominal segment IX, X and urogomphi, lateral. Abbreviations: I, II, segments of urogomphus; IX, X, abdominal segments; Ug, urogomphus. 
Table S1. Measurements of the larvae of the first $\left(\mathrm{L}_{1}\right)$ and the third $\left(\mathrm{L}_{3}\right)$ instars of $A$. ulmi $(1=$ length; w $=$ width; measurements in $\mathrm{mm}$ ).

\begin{tabular}{lllll}
\hline \multirow{2}{*}{ Characters } & $\mathrm{L}_{1}$ & \multicolumn{3}{l}{$\mathrm{L}_{3}$} \\
\cline { 2 - 5 } & $\mathrm{W}$ & $\mathrm{l}$ & $\mathrm{W}$ & $\mathrm{l}$ \\
\hline Body & - & $6.04-9.21$ & - & $12.16-17.93$ \\
& & $(8.01)$ & & $(14.70)$ \\
Head & $1.34-1.36$ & $1.16-1.37$ & $2.05-2.19$ & $1.77-2.15$ \\
& $(1.35)$ & $(1.35)$ & $(2.11)$ & $(1.94)$ \\
Pronotum & $0.87-1.05$ & $0.76-0.91$ & $1.57-1.80$ & $1.34-1.99$ \\
& $(0.95)$ & $(0.85)$ & $(1.68)$ & $(1.60)$ \\
Mesonotum & $0.96-1.11$ & $0.40-0.66$ & $1.73-2.24$ & $0.81-1.37$ \\
& $(1.05)$ & $(0.59)$ & $(1.92)$ & $(1.11)$ \\
Metanotum & $1.05-1.20$ & $0.39-0.66$ & $1.79-2.49$ & $0.62-1.22$ \\
& $(1.12)$ & $(0.52)$ & $(2.05)$ & $(0.96)$ \\
Urogomphi & & & & \\
segment I & - & $1.06-1.56$ & - & $1.70-2.41$ \\
& & $(1.23)$ & & $(2.07)$ \\
segment II & - & $0.28-0.34$ & - & $0.29-0.38$ \\
& & $(0.31)$ & & $(0.33)$ \\
terminal seta & - & $0.23-0.37$ & - & $0.19-0.23$ \\
Abdominal & - & $(0.35)$ & & $(0.22)$ \\
segment $X$ & & $1.00-1.32$ & - & $1.75-2.08$ \\
& & $(1.13)$ & & $(1.91)$ \\
\hline
\end{tabular}




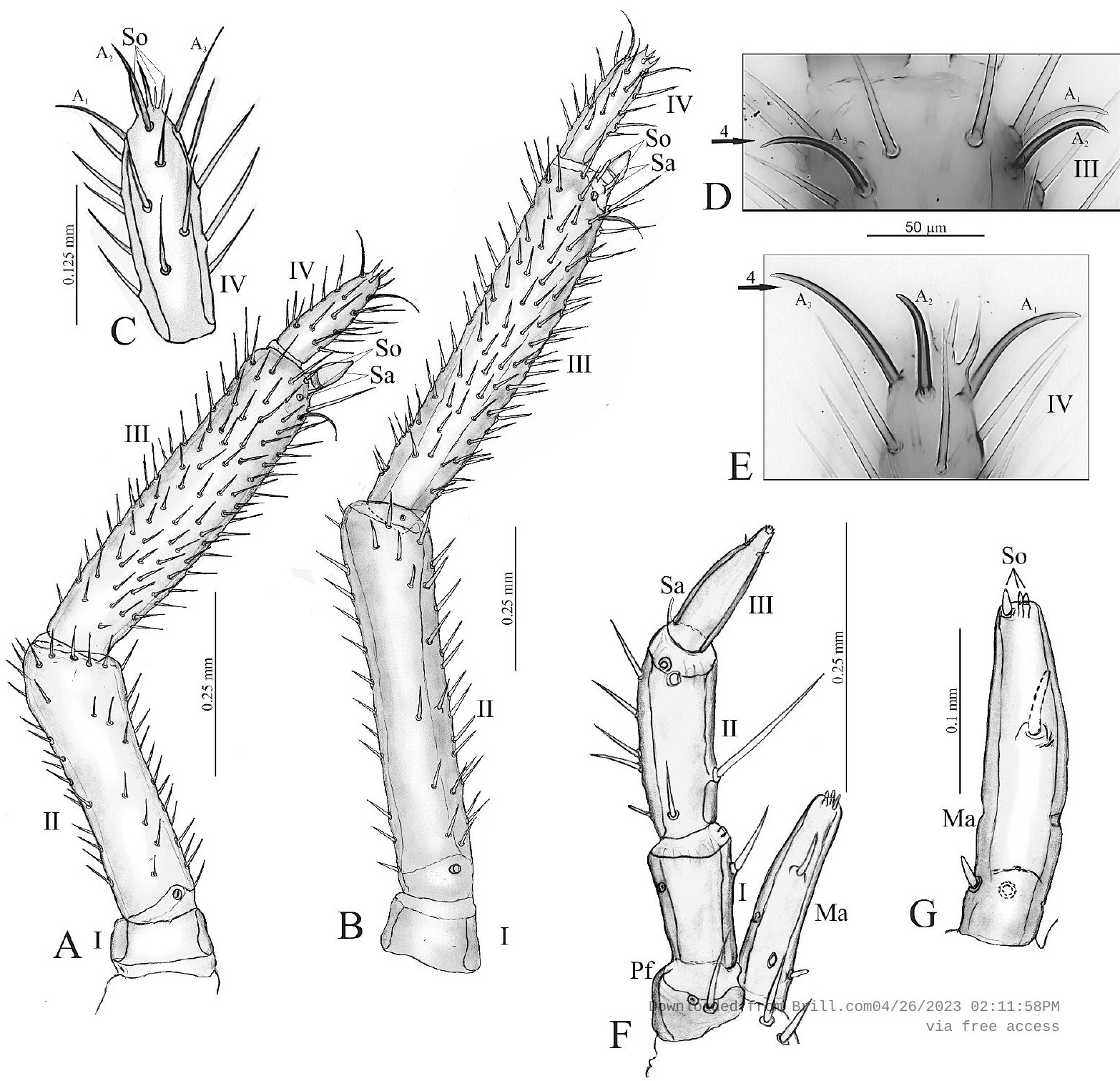



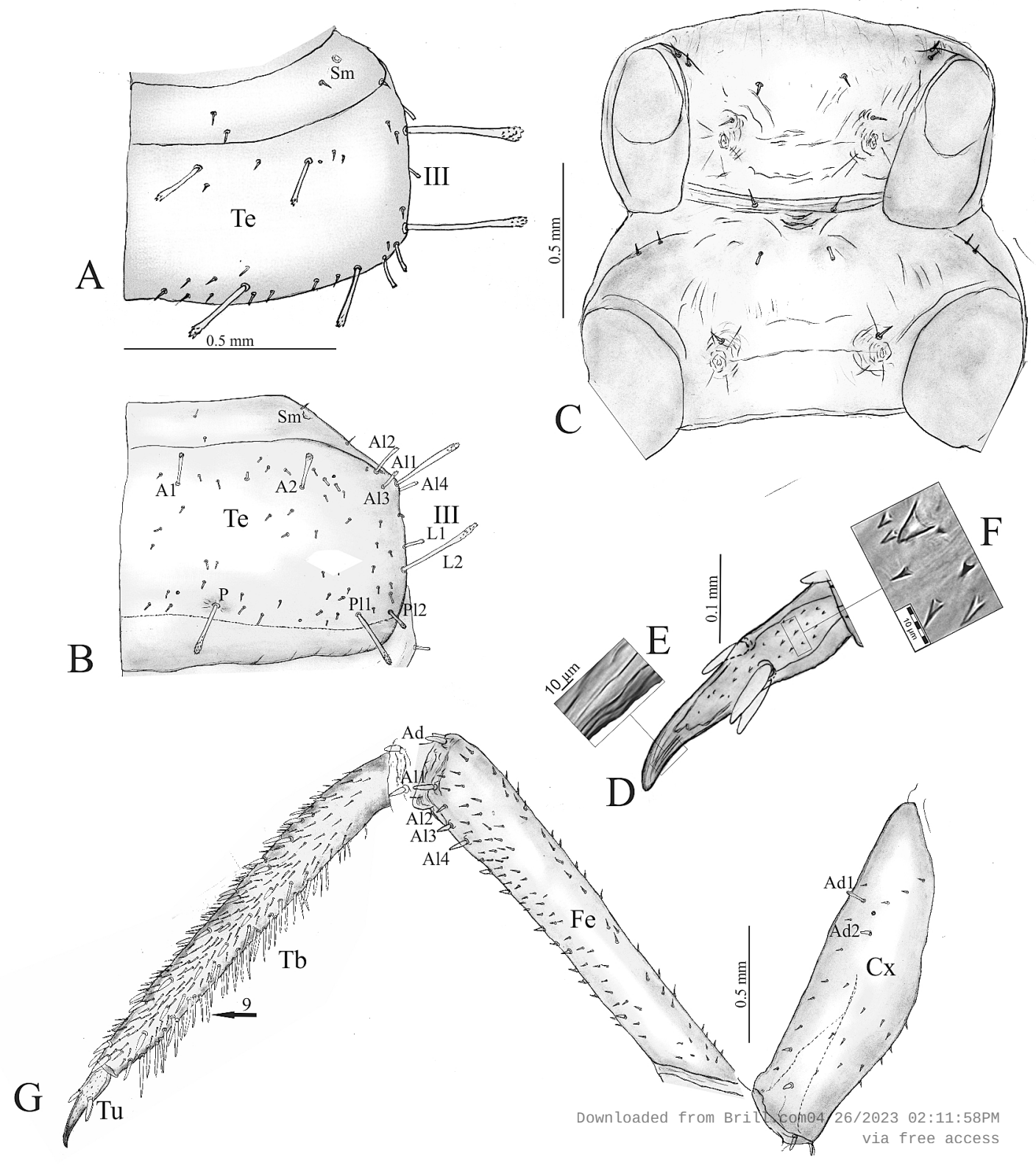
